Universidade de São Paulo

Instituto de Física

\title{
Memória: preservação de características individuais e de grupo em sistemas coerentes formados pelo acoplamento de osciladores
}

Paulo de Tarso Dalledone Siqueira

ORIENTADOR: Prof. Dr. Paulo Reginaldo Pascholati (USP)

INSTITUTODE FISICA

Serviço de Biblioteca e Informaçăo

rombo: $\frac{3822}{e x .1}$
Tese de Doutoramento

submetida ao

Instituto de Física

da Universidade de São Paulo

Banca Examinadora:

Prof. Dr. José Roberto Castilho Piqueira (Poli - USP)

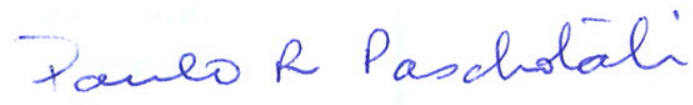

Prof. Dr. Luiz Henrique Alves Monteiro (Poli - USP)

Prof. Dr. Paulo Reginaldo Pascholati (IFUSP)

Prof. Dr. Reynaldo Daniel Pinto (IFUSP)

Prof. Dra. Vera Maura Fernandes de Lima (Funrey) 


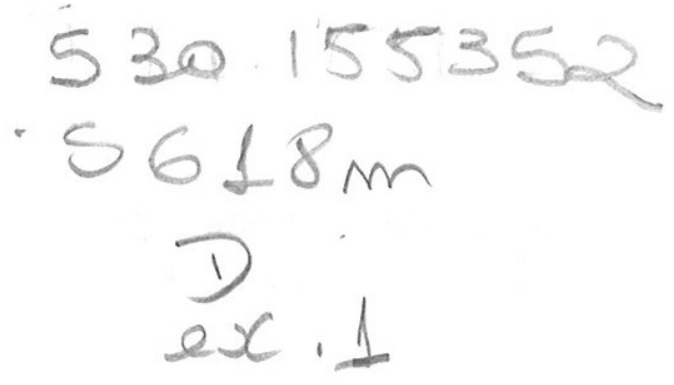

FICHA CATALOGRÁFICA

Preparada pelo Serviço de Biblioteca e Informação do Instituto de Física da Universidade de São Paulo

Siqueira, Paulo de Tarso Dalledone

Memória: Preservação de Características Individuais e de Grupo em Sistemas Coerentes Formados pelo Acoplamento de Osciladores.

São Paulo, 2003

Tese (Doutoramento) Universidade de São Paulo Instituto de Física. Departamento de Física Experimental

Orientador: Prof. Dr. Paulo Reginaldo Pascholatti Área de Concentração: Sistemas Dinâmicos

Unitermos: 1. PLL;2. Malhas de Sincronismo de Fase; 3. Small-World; 4. Sincronismo;5. Coerência. 


\section{Agradecimentos}

Várias pessoas contribuíram, nas mais diversas formas e intensidades, para que este trabalho fosse concluído às quais sou muito grato. Algumas, contudo, tiveram papel fundamental e a estas pessoas gostaria de expressar meus agradecimentos:

Ao Prof. Dr. Paulo Reginaldo Pascholati, pela amizade estabelecida ao longo dos anos, pela liberdade e pela confiança demonstrada.

Ao Prof. Dr. José Roberto Castilho Piqueira, pelas inúmeras conversas que tanto ajudaram na concepção e realização do trabalho.

Ao Prof. Fernando Orsatti, pela disponibilização do programa estruturador das malhas de PLL e pela constante assistência no aprimoramento do uso da plataforma de cálculo empregada.

Ao Ipen, nas figuras do gerente do Centro de Engenharia Nuclear, Dr. Ântonio Teixeira e Silva, e do chefe da Divisão de Física de Reatores, Prof. Dr. Adimir dos Santos, pelo apoio dadó na conclusão do trabalho.

Ao Antônio Romane pela leitura crítica do trabalho e sugestões apresentadas e pelo auxílio na concepção final do trabalho.

Aos amigos do LAL, pelo ambiente de trabalho alegre e especialmente aos amigos Antônio Carlos Hernandes, Eduardo Nascimento, Ricardo Barbosa e Ruy Morgado de Castro, pela amizade e pelas constantes ajudas.

A minha família pelo carinho e apoio de sempre.

À Roberta pela paciência, pelo carinho e pela longa convivência prazerosa. 


\section{Sumário}

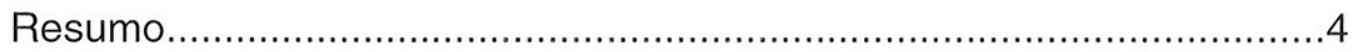

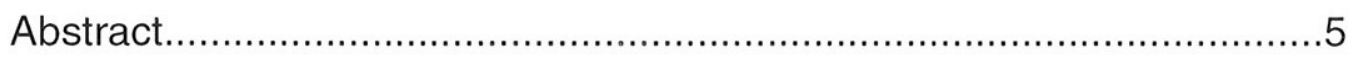

Motivação.............................................................................6

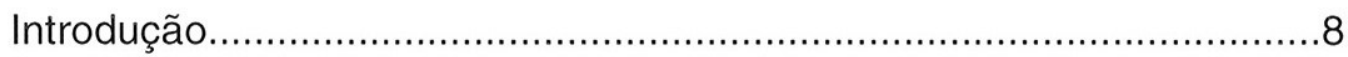

Proposta............................................................................ 11

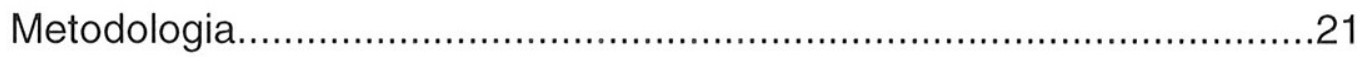

Gerador de malha...................................................21

Simulações...................................................................24

Parâmetros Secundários...................................................28

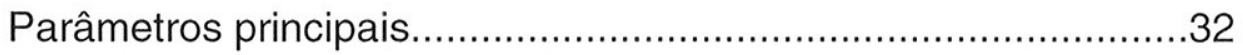

Redução de dados...........................................................43

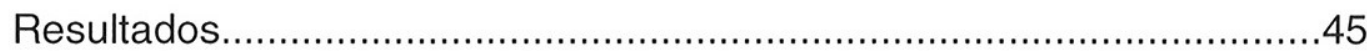

Conclusões....................................................63

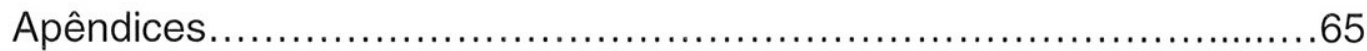

Referências bibliográficas.....................................................67 


\section{Resumo}

O presente trabalho propõe-se a oferecer respostas à questão de como a informação é preservada num sistema, focalizando-se na distinção entre os papéis desempenhados pelos constituintes elementares e pelos estruturais na preservação da memória desse sistema. Os sistemas simulados circunscreveram-se a malhas, com diferentes graus de regularidade, compostas pelo acoplamento de osciladores não-lineares que apresentam comportamento coerente no estado de equilíbrio. Malhas de Sincronismo de Fase, também conhecidas por PLLs (Phase Locked Loops), foram adotadas como elementos constituintes básicos dos sistemas analisados. Para tanto, utilizou-se a plataforma de cálculo MATLAB-SiMULINK, acompanhando-se as evoluções dos diversos sistemas e de seus parâmetros dinâmicos associados, possibilitando o estabelecimento da correspondência entre os valores dos referidos parâmetros dinâmicos com parâmetros gráficos "sensíveis" à estrutura das malhas.

Os resultados obtidos indicam a coexistência/cooperação das componentes estrutural e elementar na determinação dos valores dos parâmetros dinâmicos no estado de equilíbrio do sistema. No entanto, evidencia-se que tais componentes apresentam importâncias distintas na determinação dos diferentes parâmetros dinâmicos. 


\section{Abstract}

This work was conceived aiming to present some answers to how the information is preserved in a system. The focus was laid on the distinction between the tasks played by the elementary components and the structure of the system. The simulated systems were composed by coupled oscillators, more precisely by PLLs (Phase Locked Loops), arranged in networks of different regularities. Simulations were performed using MATLAB-SIMULINK software to build a correlation between the final state dynamical parameters of the system and its degree of regularity.

Results show the influence of both elementary and structural components on the system attained state. However the responses of characteristic parameters of the system to changes in the regularity of the structured network may greatly differ from one parameter to another. This behavior may suggest different strategies to preserve information of the system according to the information to be kept. 


\section{Motivação}

A cada 24 horas, bilhões de células de um ser humano adulto morrem [TORTORA] tendo, a cada dois anos, quase todas as suas células renovadas, exceção feita a alguns tipos de célula, a exemplo das células neuronais e das células da musculatura cardíaca. Ou seja, após dois anos o ser humano tem quase a totalidade de seus constituintes elementares substituídos por outros mais novos.

Este processo de substituição celular, que obedece a uma orientação temporal de envelhecimento/morte, é conduzido de modo que a individualidade seja preservada. Mais precisamente, não se observa, neste processo de renovação, uma descontinuidade na existência do indivíduo compatível com a envergadura da renovação ocorrida.

A partir destes fatos e de fatos análogos, poder-se-ia perguntar o que mantém tal continuidade, o que preserva a memória do indivíduo (lato sensu) conservando sua integridade. No caso do ser humano, a resposta a estas perguntas pode ser dada adotando-se pelo menos uma das seguintes linhas:

- a substituição das células é um processo contínuo, ou seja, o processo se caracteriza por diversas substituições que diferem quanto à componente elementar, à posição, além de se distinguirem temporalmente;

- nem todas as células são substituídas, pois os neurônios e as células miocárdicas, de um modo geral, não são submetidos a este processo de renovação.

Estas respostas, apesar de não serem mutuamente excludentes, são, em essência, opostas. Ao se considerar o processo contínuo, pressupõe-se uma informação contida no sistema como um todo. A substituição de parte do sistema por elementos equivalentes corresponderia apenas a uma perturbação no estado de equilíbrio deste sistema. Conquanto a amplitude desta perturbação não afaste demasiadamente o sistema de seu estado de equilíbrio, a recuperação dos parâmetros (informação) do sistema é garantida. Contudo, ao se considerar os neurônios como depositários da memória do sistema, pressupõe-se que a informação do sistema esteja alocada em nichos específicos que atuariam como pólos de informação - portanto, para cada substituição, a recuperação do equilíbrio estaria condicionada ao acesso do novo elemento aos canais específicos de informação. 
Existe, assim, uma diferença na dispersão da memória entre as linhas adotadas: uma memória do todo, com a memória permeada pelo sistema inteiro; outra, com a memória localizada pontualmente, preservada em elementos específicos do sistema.

Aceitando-se as premissas acima expostas, existe a possibilidade de extensão da associação entre memória e abrangência com a organização do sistema. Explica-se: caso a memória esteja localizada no sistema como um todo, a inter-relação entre seus constituintes elementares deve assumir um papel importante na sua preservação, pois, já que o sistema mostra-se pouco sensível a substituições de seus componentes elementares, e não havendo um provedor principal de informação a este novo elemento, deve-se creditar à vizinhança a "incorporação desse noviço" ao sistema; enquanto que, caso a memória esteja restrita a elementos específicos do sistema, a "incorporação do noviço" será sensível ao acesso da informação direcionada.

Exemplificado o caso que possibilita o questionamento do papel desempenhado pela estrutura no sistema, apresenta-se, no próximo capítulo, um panorama dos trabalhos existentes que serviram de norteadores para a redução do problema e escolha do sistema a ser analisado. A seguir expõe-se a proposta do trabalho delimitando os objetivos e, posteriormente, apresenta-se a metodologia empregada na análise do trabalho, seguida da apresentação dos resultados, comentários e conclusão. 


\section{Introdução}

A partir da motivação exposta, elegeu-se um sistema dinâmico simples (comparado ao exemplo apresentado na motivação), estável e passível de alterações que possibilitasse a investigação da interferência de sua estruturação na determinação de seus parâmetros dinâmicos a partir de algumas séries de simulações. O sistema adotado neste trabalho foi a rede formada pelo acoplamento de Malhas de Sincronismo de Fase, também conhecidas e referidas neste trabalho por PLLs (Phase Locked Loops) que, por sua vez, são dispositivos eletrônicos desenvolvidos para a obtenção do sincronismo entre dois sistemas, mais precisamente, pela sincronização do seu sinal (sinal interno) com o sinal geado por um oscilador (sinal externo). A adoção da malha de PLLs como o sistema representativo do nosso problema respalda-se em dois pontos centrais:

- o caráter oscilatório dos PLLs e

- a maior facilidade de apresentação do estado coerente do sistema.

A importância do caráter oscilatório do sistema reside principalmente na manifestação do padrão oscilatório em diversos sistemas das mais variadas naturezas.

Deve-se particularmente à manifestação do caráter oscilatório em sistemas biológicos, em seus diversos níveis de organização, o grande interesse despertado junto à comunidade científica [GLASs]. A vitalidade das células, por exemplo, está associada a sua capacidade de interação com o meio externo, a qual é caracterizada por um constante fluxo de matéria e energia. Esta dinâmica permite a formação de oscilações químicas que podem (ou devem) responder por importantes mecanismos bio-regulatórios [KINDZELSKII].

Especial interesse tem sido demonstrado por sistemas que apresentam o afloramento da coerência, e eventualmente do sincronismo - onde se acresce à igualdade das frequiências de oscilação dos distintos osciladores a concordância de fases. Este é um fenômeno há tempo relatado e tem sido empregado para modelar sistemas de naturezas tão distintas como neurobiologia [SATOH, KOPELL], dinâmica populacional [BUCK], reações químicas [KURAMOTO], inteligência artificial [AOYAGI,HOPPENSTEADT].

No estudo de sistemas oscilatórios, estes são geralmente representados por um conjunto de osciladores, representando seus elementos básicos, que conferem unidade ao conjunto através do acoplamento entre os osciladores. O interesse pelo acoplamento de 
osciladores é antiga, com relatos datados de 1665 [HUYGENS], contudo a expansão para o tratamento de sistemas compostos por uma população de osciladores foi grandemente facilitada por [WINFREE] que propôs um modelo que reduziu o número de variáveis a serem tratadas na análise do sistema, basicamente a fase de cada oscilador.

Kuramoto, numa extensão aos trabalhos de Winfree propôs um modelo onde os acoplamentos entre os osciladores são simétricos e dependente da diferença entre as fases e não da fase, como proposto por Winfree. Numa população de osciladores de Kuramoto, osciladores, cuja distribuição de frequiências naturais obedeça a uma distribuição unimodal, a "convergência" do sistema é limitada pela relação entre a intensidade dos acoplamentos (assumido como independente das conexões) e a largura característica da distribuição de frequiências. Porém, obtida a convergência do sistema, observam-se dois comportamentos distintos entre os osciladores do sistema. Aqueles osciladores cujas freqüências características encontram-se nas proximidades da frequiência de pico da distribuição de freqüências (wo) sincronizam-se com freqüência wo. Contudo, aqueles osciladores cujas freqüências características encontram-se além das proximidades de wo (o valor determinante da proximidade depende tanto do ganho como da largura da distribuição de frequiências) têm suas frequiências alteradas, mas não sincronizadas. Os valores de suas freqüências aproximam-se de wo e oscilam em torno deste valor caracterizando o selfentrainment deste conjunto de osciladores.

Portanto, a princípio, condicionava-se a obtenção do comportamento coerente do sistema unicamente à intensidade de acoplamento e à distribuição das freqüências naturais dos osciladores. Esta limitação respaldava-se pelos sistemas analisados, usualmente regulares [DE SOUZA VIEIRA, GOLDZSTEIN].

Alguns estudos, porém, abordaram a dependência do valor da intensidade de acoplamento com a estrutura do sistema - formado pelo acoplamento de um grande número de osciladores - para a manifestação de um comportamento global, caracterizado pelo estado coerente [SATOH,WATTS, LAGO-FERNADEZ].

Satoh, em simulações de sistemas constituídos por osciladores de van der Pol, verificou que o surgimento do comportamento global é mais eficiente e mais sensível a pequenas alterações na intensidade de acoplamento em malhas aleatórias (random graphs) do que em malhas regulares. Watts, em simulações de sistemas formados por osciladores de 
Kuramoto - osciladores cuja freqüência de oscilação depende, além da freqüência natural, da diferença entre as fases dos osciladores acoplados - numa extensão à idéia de Satoh, estudou a relação entre o grau de regularidade da malha e o valor mínimo da intensidade de acoplamento entre os osciladores para o surgimento do estado coerente.

LAGO-FERNADEZ ET AL. em estudos da regularidade topológica da rede mostram que as malhas com regularidades intermediárias, mais precisamente aquelas com topologias de small-world, conjugam a apresentação do padrão coerente com o tempo de estabilização do sistema (transiente) pequeno. 


\section{Proposta}

O presente trabalho focaliza-se na caracterização do estado coerente, buscando estabelecer uma correspondência entre este estado e as condições iniciais do sistema (regularidade da malha e caracterização dos osciladores). A restrição do estudo à sistemas coerentes visa a representação de sistemas que tenham uma dinâmica que possibilite uma correspondência biológica, mas não necessariamente restrita à mesma, e que também apresentem uma continuidade dinâmica. Esta restrição justifica a escolha das malhas de sincronismo de fase como representantes dos sistemas a serem analisados.

PLL, componente elementar do sistema escolhido, é um dispositivo eletrônico projetado para "sincronizar" o seu sinal de saída com o sinal de entrada. Fundamentalmente, um PLL é composto por três componentes:

1. um detector de fase;

2. um filtro passa-baixas e

3. um oscilador controlado por voltagem (VCO - Voltage Controlled Oscilator) (figura 1).

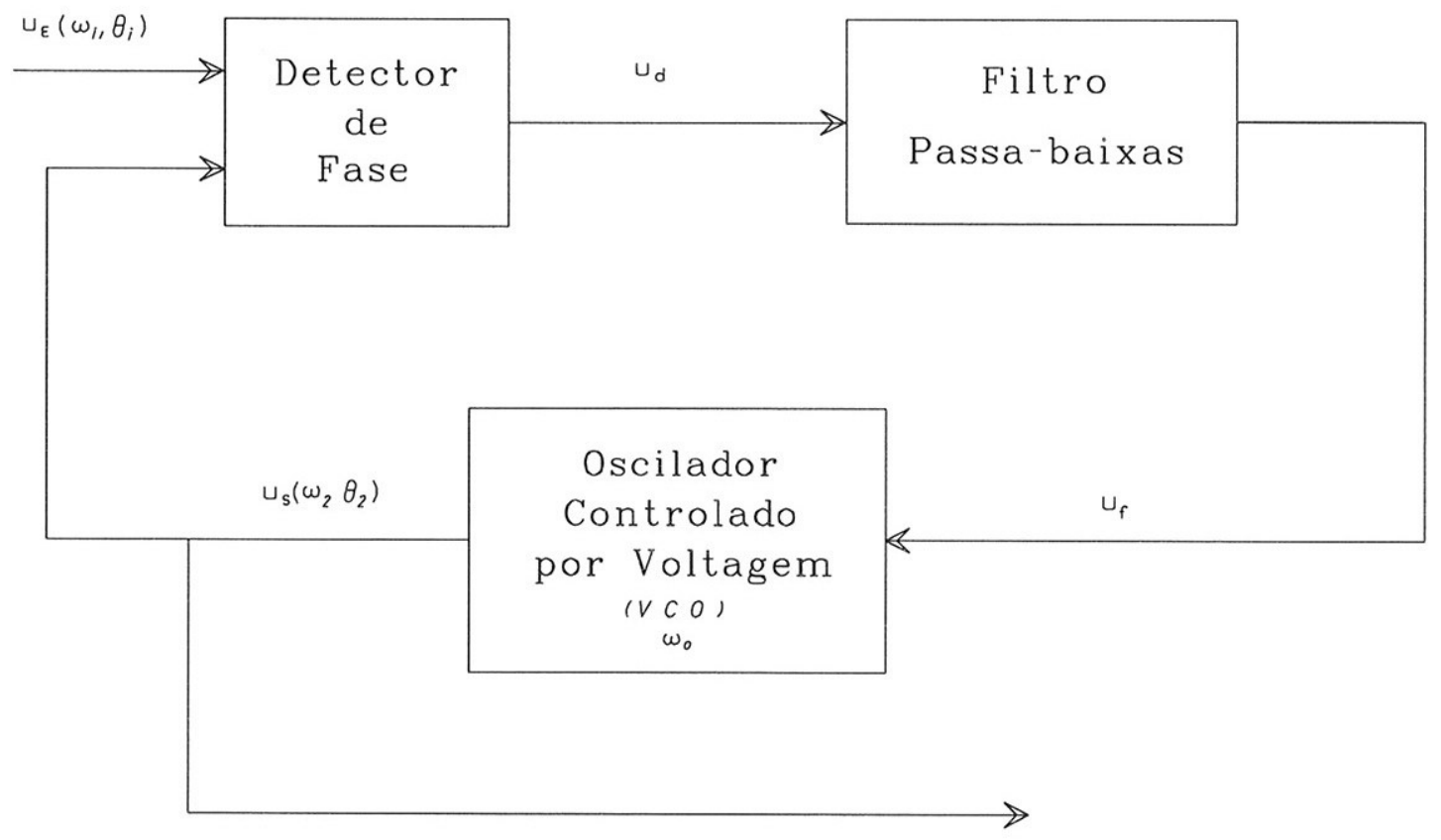

Figura 1: Diagrama esquemático de um PLL. 
O detector de fase é um multiplicador analógico que desempenha a função de comparar as fases dos sinais de entrada $\left(u_{i}\right)$ e interno $\left(u_{\ell}\right)$. Sejam estes sinais dados respectivamente por:

$$
\begin{aligned}
& u_{i}(t)=A_{i} \cdot \sin \left[w o \cdot t+G_{i}(t)\right] \\
& u_{o}(t)=A_{o} \cdot \cos \left[w o \cdot t+\theta_{o}(t)\right]
\end{aligned}
$$

onde $A_{i}$ e $A_{o}$ são as intensidades máximas dos sinais e wo é a freqüência central do sinal $u_{i}$. O sinal do detector de fase é dado, portanto, por:

$$
u_{d}(t)=K_{d} \cdot u_{i}(t) \cdot u_{o}(t)
$$

onde $K_{d}$ é o ganho deste componente. Desenvolvendo este termo, tem-se:

$$
u_{d}(t)=\frac{K_{d} \cdot A_{i} \cdot A_{o}}{2} \cdot\left\{\sin \left[\theta_{i}(t)-\theta_{o}(t)\right]+\sin \left[2 \cdot w o \cdot t+\theta_{i}(t)+\theta_{o}(t)\right]\right\} .
$$

É procedimento comum, desprezar o termo de freqüiência dupla [BEST], presumindose sua supressão ao passar pelo filtro passa-baixas, cuja função de transferência, expressa em função da frequiência $(s)$, é dada por:

$$
F(s)=\frac{L\left\{u_{f}\right\}}{L\left\{u_{d}\right\}}=\frac{w o}{\sigma . s+w o}
$$

onde $L\left\{u_{f}\right\}$ e $L\left\{u_{i}\right\}$ são, respectivamente, as transformadas de Laplace de $u_{f}$ e $u_{i}$, e $\sigma$ é um termo proporcional à resistência e à capacitância do filtro.

Sendo a resposta do VCO, mais precisamente sua freqüência, proporcional ao sinal de saída do filtro $\left(u_{f}\right)$;

$$
G_{o}(t)=K_{o} \cdot u_{f}(t)
$$


Combinando-se as expressões acima, e aceitando a consideração para a exclusão do termo de frequiência dupla, pode-se descrever a dinâmica do PLL a partir da seguinte equação:

$$
\sigma \cdot \ddot{\theta}_{o}+w o \cdot \dot{\theta}_{o}=\frac{w o \cdot K_{o} \cdot K_{d} \cdot A_{i} \cdot A_{o}}{2} \cdot \sin \left(\theta_{i}-\theta_{o}\right)
$$

Basicamente, o VCO gera um sinal cuja fase $\left(\theta_{o}\right)$ é dependente da fase do sinal de entrada $\left(G_{i}\right)$. Idealmente, a freqüência do sinal interno se iguala à do sinal de entrada para uma certa diferença de fase. O conceito de "sincronismo" restringe-se aqui apenas a oscilações na mesma frequiência, não havendo necessariamente a coincidência nas fases.

Analogamente aos osciladores de Kuramoto, a frequiência de oscilação dependente de um termo proporcional à diferença entre as fases do sinal de entrada $\left(\theta_{i}\right)$ e o sinal interno $\left(G_{o}\right)$, porém a vantagem do emprego dos PLLs frente a simples osciladores (osciladores de Kuramoto) é a capacidade intrínseca daqueles alterarem sua freqüência de oscilação conforme os sinais de entrada. Obtém-se, assim, uma população de osciladores cuja distribuição de freqüências estreita-se possibilitando a sincronização do sistema. Todavia, a capacidade de sincronização de um PLL, caracterizada por sua faixa de captura (capture range), depende da eficiência do seu filtro para que o PLL opere na região linear.

No ano 2000, HoPPENSTEADT propôs a utilização da malha de sincronismo de fase como uma rede neural oscilatória, onde os padrões a serem reconhecidos são associados à distribuição das fases dos diferentes PLLs da malha. A principal proposição de seu trabalho é a afirmação da convergência da rede (sistema) para um estado coerente, isto é, com o "travamento" da diferença entre as fases (phase locking) dos PLLs, para PLLs com freqüências naturais $(\Omega \gg>1$ ) iguais e funções resposta $(V)$ periódicas (módulo $2 \pi$ ) e que satisfaçam à condição designada com odd-even dada por:

$$
V(-\theta)=-V(\theta) \quad \text { e } \quad V(-\theta-\pi / 2)=-V(\theta-\pi / 2) .
$$

Em 2003 PIQUEIRA ET AL. mostram, entre outros aspectos, que para uma malha de sincronismo de fase com 4 PLLs, a dependência da freqüência de oscilação do estado 
coerente com o ganho dos PLLs (considerados iguais) bem como como a possibilidade de obtenção do estado coerente para uma distribuição de freqüência de livre curso (freqüência natural de oscilação de cada PLL), mostrando a possibilidade de aplicação da idéia de Hoppensteadt para condições mais amplas.

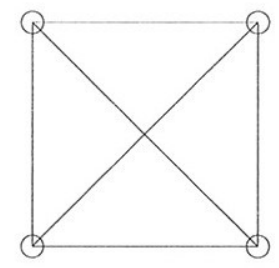

Figura 2: Diagrama esquemático da rede de 4 PLLs analisada no trabalho de PIQUEIRA ET AL.

Este trabalho, numa extensão aos trabalhos supra-citados, contempla o estudo da influência da topologia das malhas de sincronismo de fase na determinação dos parâmetros dinâmicos do sistema

Para auxiliar no dimensionamento e na quantificação da regularidade de estruturação dos sistemas, foram utilizados alguns parâmetros da teoria dos grafos.

Grafo é, no seu conceito mais primário, um conjunto de pontos interligados por linhas (figura 3). Mais, precisamente, grafo - segundo WILSON E WATKINS - "consiste em um conjunto não vazio de elementos, chamados de vértices, e uma lista de pares não ordenados destes elementos, chamados de borda. Se $v$ e $w$ são vértices de um grafo G, então diz-se que uma borda da forma $v w$ une ou conecta dos vértices $v$ e $w$ ". Apesar dos elementos dos grafos serem explicitamente designados por vértices e bordas naquela definição, estas terminologias não são únicas, sendo utilizados também as seguintes terminologias: ponto-linha, nó-arco, junção-ramo, 0-simplex-1-simplex, elemento-elemento. 


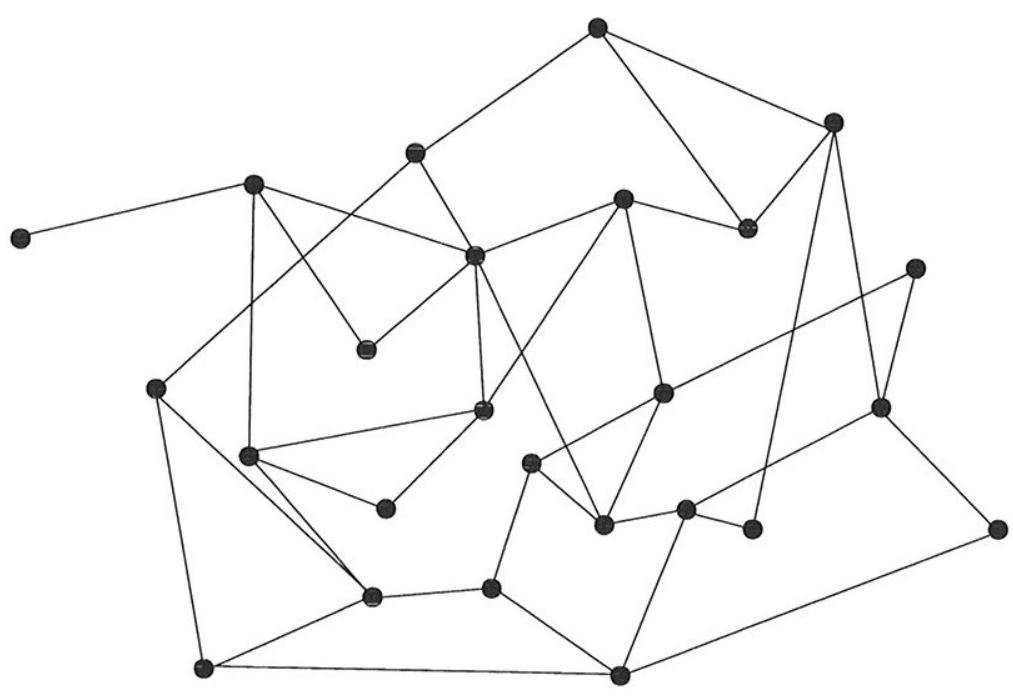

Figura 3: Grafo em seu conceito mais elementar: os pontos representam os vértices e as linhas, bordas.

A possibilidade de construção de grafos com um número qualquer de nós $(N$, designado como ordem do grafo) e arcos ( $M$, designado como tamanho do grafo) permite a representação de qualquer tipo de sistema onde os elementos se inter-relacionam. Os vértices podem representar estes elementos e as bordas as relações, sejam eles e elas quais forem (pessoas-amizade, países-relações comerciais, servidores de internet-conexões, cidades-estradas, geradoras de energia-rede de distribuição, etc.).

Existe, contudo, algumas classes de grafo que desempenham papel de relevância na estruturação do presente trabalho: grafos regulares e grafos aleatórios. Esta classificação restringe-se à construção de arcos num grafo.

Nos grafos regulares, também chamados de lattice graphs ou d-lattices, a construção dos arcos obedece a uma regra definida em função dos parâmetros:

- $\quad k$, grau médio do grafo, que é a média, entre todos o nós, do número de conexões existentes por vértice:

$$
k=\frac{2 \cdot M}{N} \mathrm{e}
$$

- $d$, dimensão do grafo.

Para $d=1$ e $k=2$ tem-se um anel, para $d=2$ e $k=4$ tem-se um reticulado quadrado (figura 4). 

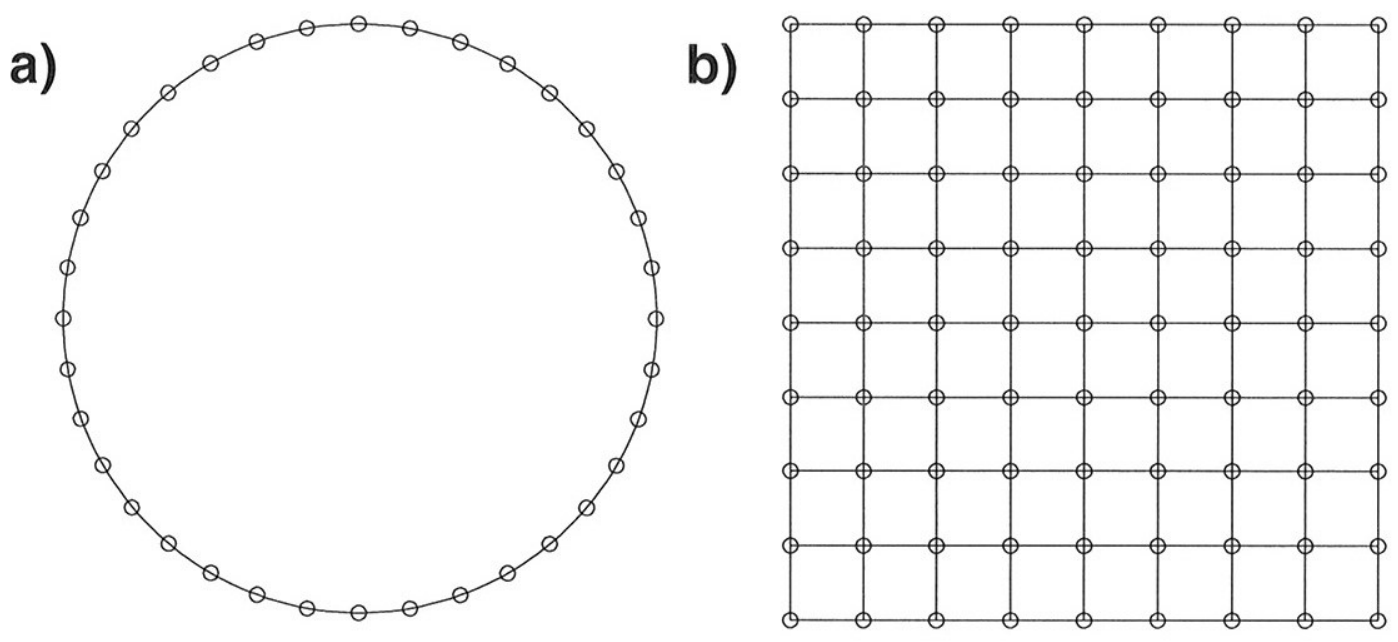

Figura 4: Grafos regulares. a) dimensão $(d) 1$ e grau $(k) 2$; b) $d=2, k=4$ (com extremidades periódicas).

Os grafos aleatórios, por sua vez, têm seus arcos construídos de uma maneira aleatória. Porém, as estratégias de construção destes grafos podem ser distintas. Pode-se fixar o número de $\operatorname{arcos}(M)$ do grafo e alocá-los aleatoriamente, ou pode-se fixar a probabilidade $0 \leq p \leq 1$ de existência de cada um dos $N .(N-1) / 2$ arcos passíveis de serem formados.

No caso específico deste trabalho, os pontos representam os PLLs e as linhas as conexões existentes entre os PLLs, a ausência de uma linha entre dois nós indica a inexistência de uma conexão entre eles. Apesar dos grafos representarem esquematicamente as relações entre os elementos, derivando daí boa parte de sua terminologia, usou-se neste trabalho, como em boa parte dos trabalhos computacionais, uma Matriz de Conexão (adjacency matrix). Uma matriz de conexão $M(\mathrm{G})$, que representa uma grafo $\mathrm{G}$ de ordem $N$, é uma matriz $N \times N$ onde os elementos $M_{i, j}$ assumem o valor igual a 1 caso haja uma conexão entre os nós $i$ e $j$ ou, no caso da inexistência da conexão entre estes nós, assumem o valor igual a 0.

Os parâmetros adotados foram:

- $\quad$ Comprimento Característico $(L)$, que é a média das distâncias entre todos os pares de nós, passíveis de serem montados no grafo. A distância considerada $\left(L_{i, j}\right)$ refere-se a uma 
métrica particular dos grafos, mais precisamente ao número mínimo de arcos que devem ser percorridos para que dois nós distintos $(i$ e $j)$ se relacionem.

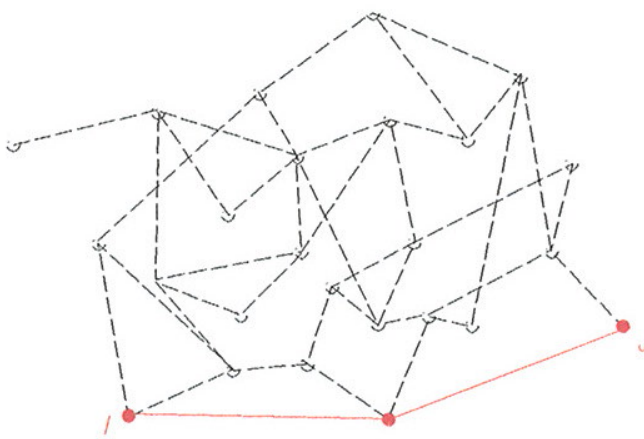

$$
L=\frac{1}{N \cdot(N-1)} \cdot \sum_{i, j}^{N} L_{i, j}
$$

Figura 5: Exemplo da métrica utilizada na avaliação do Comprimento Característico $(L)$ do grafo apresentado na figura 3. A menor distância entre os nós $i$ e $j$ é apresentada na figura pelos arcos vermelhos $\left(L_{I, J}=2\right)$.

- $\quad$ Clickshness $(\gamma)$, também conhecido por Clustering Coefficient (coeficiente de agrupamento), que é a média, entre todos os nós, da proporção de interconexões existentes - entre às possíveis, numa vizinhança, onde a vizinhança de um nó $i$ corresponde ao conjunto de nós que se encontram à distância de um arco do nó $i$. Ou seja, para um nó $i$ com $k_{i}$ nós vizinhos, existe a possibilidade de haver $k_{i} \cdot\left(k_{i}-1\right) / 2$ conexões entre estes nós. Sendo $\gamma_{i}$ a fração destas conexões que existem de fato, $\gamma$ é dado pela média de todos os $\gamma_{i}$.

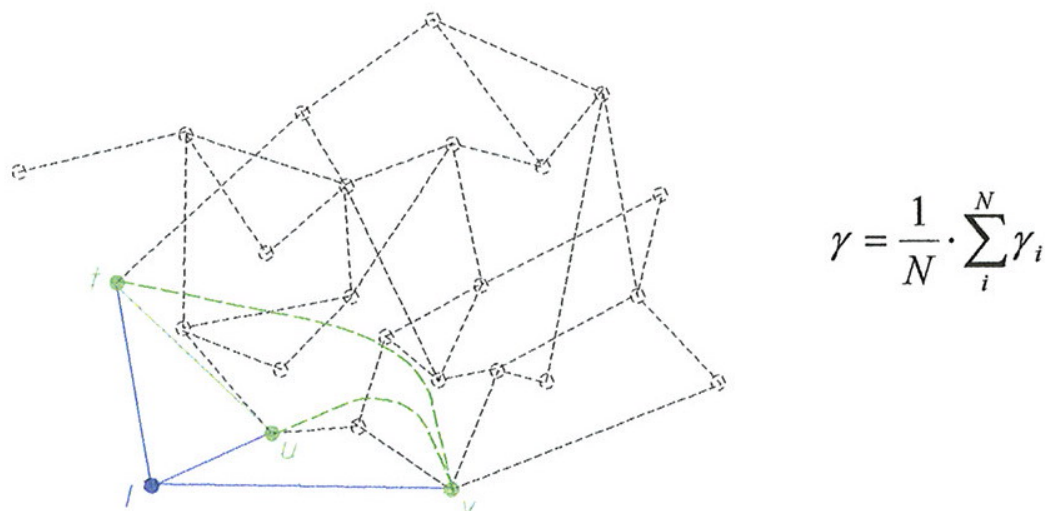

Figura 6: Exemplo da métrica utilizada na avaliação do Clickshness ( $\gamma$ ) do grafo apresentado na figura 3. A vizinhança do nó $i$ é composta por aqueles nós que se encontram à distância de um arco do nó $i$ (nós $t, u$ e $v:$ em verde). Entre os 3 possíveis arcos a conectar estes nós (em verde), existe apenas um (traço verde contínuo). $\left(\gamma_{I}=1 / 3\right)$. 
A adoção dos parâmetros $L$ e $\gamma$ justifica-se pela distinção de respostas apresentadas por estes parâmetros frente a diferentes graus de alteração das malha. Apresenta-se, na figura 5, a dependência destes parâmetros com a regularidade da malha para grafos com $N=40,100,500$ e 1000, onde a caracterização da regularidade da malha pode ser expressa para os grafos aleatórios através do parâmetro $p$, que corresponde à probabilidade de alteração dos arcos de um grafo regular. Tem-se, para $p=0$, uma malha regular.

Observa-se, nesta figura, uma relação inversa dos parâmetros $L$ e $\gamma \operatorname{com} p$, pois os valores daqueles diminuem com o aumento da irregularidade do grafo (associada ao aumento de $p$ ). Verifica-se, contudo, comportamentos diferentes para $L$ e $\gamma$ em relação à variação da regularidade da malha pois, enquanto $L$ apresenta a redução de seu valor para pequenos valores de $p, \gamma$ manifesta este comportamento para valores de $p$ mais altos. Esta diferença é tão mais intensa quanto maior o valor de $N$, pois $L$ é um parâmetro que expressa características globais, apresentando grande sensibilidade a pequenas alterações da malha regular e a sua ordem $(N)$. Por sua vez, $\gamma$ mostra-se sensível apenas a elevados graus de alteração da malha pois constitui-se num parâmetro inerentemente associado às características locais da malha, não alterando seu valor para grafos regulares de mesmo grau médio $(k)$ e ordens diferentes (tabela 1$)$.

Tabela 1: Valores de $L$ e $\gamma$ para malhas regulares $(p=0)$ para grafos de diferentes ordens e mesmo grau médio $(k=4)$.

\begin{tabular}{|c|c|c|}
\hline$N$ & $\boldsymbol{L}$ & $\gamma$ \\
\hline 40 & 5,3846 & 0,5 \\
\hline 100 & 12,8789 & 0,5 \\
\hline 500 & 62,8757 & 0,5 \\
\hline 1000 & 125,3758 & 0,5 \\
\hline
\end{tabular}



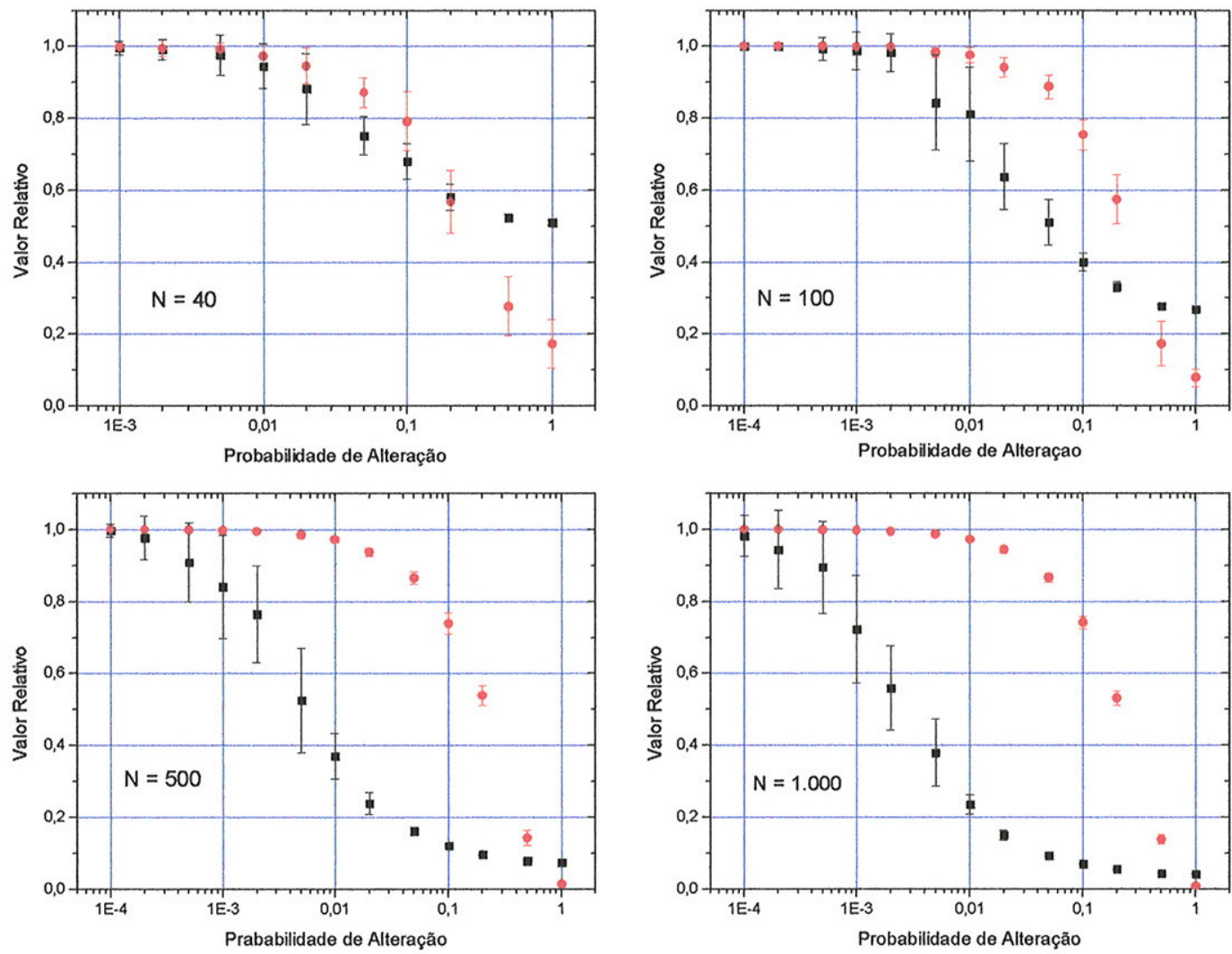

Figura 5: Perfis de comportamento dos parâmetros $L$ (quadrados pretos) e $\gamma$ (círculos vermelhos) frente à variação da regularidade das malhas (expressa pela probabilidade de alterações dos arcos da malha regular $-p)$ de diferentes ordens $(N=40,100,500$ e 1000) e mesmo grau médio $(k=4)$.

Considerando-se a amplitude de sistemas que os grafos podem representar, foram considerados neste trabalho, apenas os grafos que atenham as seguintes condições:

a. que todos seus nós estejam conectados à rede - grafos conexos;

b. que a quantidade de conexões seja muito inferior ao número de distintos pares passíveis de serem construídos - grafos esparsos;

c. que as conexões sejam simétricas, ou seja, toda e qualquer conexão entre dois vértices deve apresentar reciprocidade (uma relação de mão-dupla);

d. que as conexões sejam simples, onde mais de uma conexão entre o mesmo par de nós é proibida - multigrafos são descartados; 
e. que sejam vedadas conexões ligando um nó a si mesmo - pseudografos também são desconsiderados;

f. que todas as conexões tenham sempre a mesma intensidade. 


\section{Metodologia}

Como o objetivo deste trabalho é estabelecer uma associação entre a organização de um sistema com os valores de alguns de seus parâmetros dinâmicos no estado de equilíbrio, simularam-se os comportamentos dos sistemas compostos por malhas de PLLs com diferentes graus de regularidade.

A partir dos resultados destas simulações extraíram-se os valores dos referidos parâmetros, possibilitando o estabelecimento de uma correspondência entre os parâmetros estáticos - referentes às características da malha -, com os parâmetros dinâmicos referentes às características de operação do sistema no estado de equilíbrio.

Foram criadas, portanto, alguns grafos regulares, com dimensão 1, de mesmo grau médio $(k=4)$, mas com diferentes valores de ordem $(N=40,100,500$ e 1000). A partir de um determinado grafo regular criaram-se novos grafos aleatórios com diferentes graus de regularidade. O procedimento de criação destes novos grafos fundamentou-se na alteração das conexões do grafo regular existente, preservando-se os números de nós $(N)$ e de conexões $(M)$, mantendo-se, desta maneira, os valores da ordem e do grau médio. A amplitude no número de alterações efetuadas foi controlada por um parâmetro $p$, correspondente à probabilidade de ocorrência da alteração de uma conexão, estendendo-se a todas as conexões da malha a verificação da ocorrência deste evento para o mesmo valor de $p$. A diversidade nos graus de regularidade da malha foi obtida a partir do emprego deste procedimento com a adoção de diferentes valores do parâmetro $p$. Como este procedimento de criação de grafos aleatórios não garantia a conectividade do grafo, toda malha criada teve sua conectividade verificada antes de ser caracterizada (determinação de $L$ e $\gamma$ ). Para a condução desta etapa, contou-se com utilização de um programa gerador de malha.

\section{Gerador de malhas}

O programa Gerador de Malhas gera um grafo regular, mais precisamente uma Matriz de Conexão (adjacency Matrix) a partir de dados de entrada ( $N$, ordem do grafo e $k$, grau médio), com dimensão 1, apresentando os parâmetros $L$ e $\gamma$.

Cada nó da malha é representado por uma linha e uma coluna da Matriz de Conexão e as indicações da existência ou não da conexão entre os nós $i$ e $j$ são fornecidas pelo 
elemento $M_{i j}$ desta matriz. Em função das condições quanto aos grafos tratados neste trabalho, condições explicitadas nas páginas 19 e $20, M_{i j}$ assume o valor igual a 1 no caso da existência de uma conexão entre os nós $i$ e $j$ (condições $\mathbf{d}$ e f) e 0 em caso contrário. Em função da reciprocidade das relações e da exclusão de pseudo-grafos (respectivamente, condições c e e), a Matriz de Conexão é simétrica $\left(M_{i j}=M_{j i}\right)$ e tem os elementos da sua diagonal principal zerados $\left(M_{i i}=0\right.$, para qualquer $\left.i\right)$.

Os parâmetros $L$ e $\gamma$, apesar da possibilidade de serem calculados explicitamente nas condições encontradas acima (látice regular de dimensão 1), são obtidos por um procedimento desenvolvido para calculá-los quaisquer que sejam as condições do grafo.

Num passo inicial determina-se a lista de conexões (adjacency list) de cada nó. A lista de conexão de um nó $j$ qualquer é dada por um vetor cujos elementos assumem os valores dos identificadores dos nós que compõem a vizinhança do nó $j$. Ou seja, a lista de conexões de um nó $j$ é composta pelos valores de $i$ para os quais $M_{j i}=1$, que são os elementos não nulos da coluna $j$ da Matriz Conexão.

A seguir, procuram-se os segundos vizinhos (pontos separados por dois arcos) de cada nó da malha. A procura do segundo vizinho de um nó $j$ qualquer baseia-se na consulta às listas de conexão dos nós que compõem a sua vizinhança (primeiros vizinhos). Todo nó que conste em qualquer uma destas listas consultadas e que não seja um nó vizinho a $j$, constitui-se num segundo vizinho de $j$. Prossegue-se procurando os terceiros vizinhos (pontos separados por três arcos), quartos vizinhos (quatro arcos de separação) e assim por diante até que as distâncias entre todos os pares de nós da malha tenham sido determinadas.

O controle deste procedimento é efetuado através de uma matriz auxiliar cujos elementos $A_{i j}$ assumem valor igual a: 1 para nós vizinhos $\left(A_{i j}=M_{i j}\right.$, para $\left.M_{i j} \neq 0\right)$, 2 para segundos vizinhos, 3 para terceiros vizinhos, etc. Este procedimento se repete até o momento em que todos os elementos desta matriz auxiliar são avaliados ou algum de seus elementos assume valor superior a sua ordem, o que corresponderia à existência de um nó desconectado. Esta matriz auxiliar, à semelhança da Matriz de Conexão, é simétrica e tem todos os elementos da diagonal principal com valor nulo. Portanto, com o intuito de agilizar os cálculos e sem o comprometimento de seus resultados, a avaliação resume-se a uma de suas metades. 
O cálculo do comprimento característico é obtido pela média dos valores dos elementos da matriz auxiliar, excetuando-se, obviamente os elementos da diagonal principal.

O cálculo do Clickshness é efetuado pela média das proporções de coincidências existentes entre as listas de conexão de uma determinada vizinhança.

Criado e caracterizado o grafo regular, com a determinação dos parâmetros $L$ e $\gamma$, existe a possibilidade de criação dos grafos aleatórios com diversos graus de regularidade. Estes grafos são criados a partir de alterações das conexões da malha regular existente, num processo em que cada conexão da malha regular é sujeita, com uma probabilidade definida $p$, à ocorrência de uma alteração. As novas conexões criadas, na substituição àquelas alteradas/removidas, não são propriamente aleatórias, pois um dos nós da conexão alterada, participa como um dos elementos do par de nós que caracteriza a nova conexão. Este procedimento em analogia ao proposto por Watts procura propiciar a criação de grafos conexos. Contudo, no procedimento adotado neste trabalho, não se definiu, a priori, o nó mantido na conexão alterada. Esta opção apesar de não garantir a conectividade dos grafos "aleatórios" criados garante uma maior riqueza nos grafos gerados.

Portanto, verificada a ocorrência da alteração de uma conexão da malha regular (por um sorteio/amostragem aleatória), um novo processo se inicia buscando as definições do nó que será preservado na conexão e do novo nó que comporá o par que define a nova conexão.

A obtenção de malhas aleatórias com diferentes graus de regularidade é obtida pela adoção de diferentes valores de $p$ (figura 6). Os parâmetros de controle de alteração disponíveis restringem-se ao valor da probabilidade de existência da alteração e ao número de vezes em que se deseja repetir este procedimento.

em seus diversos graus de regularidade.

Em função da possibilidade de criação de uma grande variedade de grafos aleatórios, a partir de um único grafo regular, para um mesmo valor de $p$, o programa gerador de malhas verifica a sua conectividade de cada grafo criado, pela verificação da montagem completa da matriz auxiliar, e determina os valores de $L$ e $\gamma$ que caracterizam o novo grafo. 

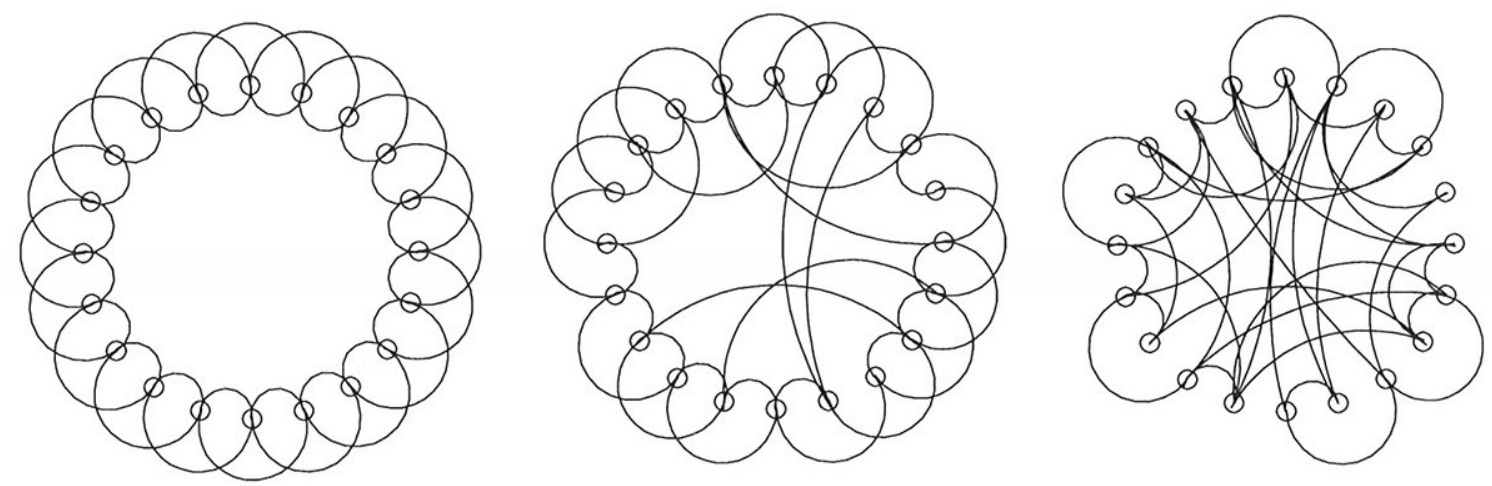

Figura 6: Grafos de mesmo grau médio $(k=4)$ e mesma ordem $(N=20)$, mas com diferentes graus de regularidade. A criação de grafos aleatórios com níveis decrescentes de "organização" é obtida com a adoção de valores crescentes de $p$ (probabilidade de alteração de uma conexão da malha regular). $O$ grafo da extrema esquerda é um grafo regular $(p=0)$.

Em função dos parâmetros de rede $(L$ e $\gamma)$ apresentarem respostas diferentes para malhas de mesmo grau médio, mas de diferente ordem (figura 2), estendeu-se os estudos à análise de malhas com valores distintos de ordem. Os sistemas estudados foram aqueles para $k=4$ e $N=40,100,500$ e 1000 .

\section{Simulações}

As simulações deste trabalho foram executadas dentro da plataforma de cálculo MATLAB-SimulinK [HANSELMAN]. Esta plataforma disponibiliza uma biblioteca de estruturas matemáticas, agrupadas em blocos, que, pela concatenação dos diferentes blocos, associada à flexibilidade na caracterização dos mesmos, permite a representação de uma grande variedade de sistemas das mais diversas naturezas e complexidades.

A figura 7 mostra como cada PLL foi montado a partir das estruturas disponibilizadas na referida plataforma de cálculo. 


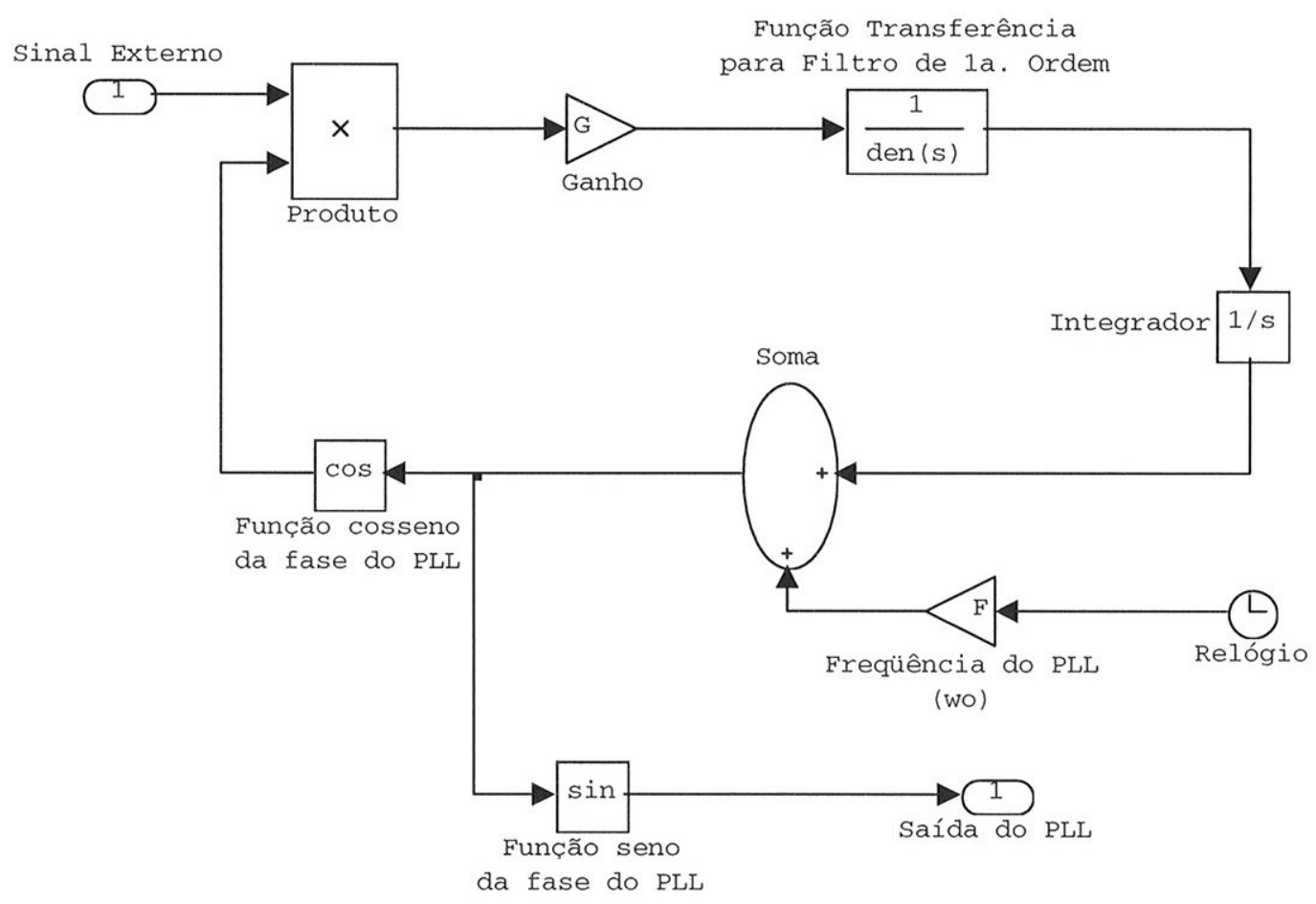

Figura 7: Diagrama de blocos, construídos na plataforma MATLAB-SIMULINK para representar um PLL.

A associação de um multiplicador (bloco Produto) dos sinais de entrada (Sinal Externo e Função co-seno da fase do PL, respectivamente ue e us da figura 1) com um amplificador de sinal (bloco Ganho) constrói-se o detector de fase do PLL. O filtro passabaixas é representado pelo bloco função de transferência, onde se emprega um filtro de primeira ordem dado $1 / \operatorname{den}(s) \mathrm{com} \operatorname{den}(s)=1+2 \cdot \pi \cdot s /$ wo . O Oscilador Controlado por Voltagem ( $V C O)$ é formado pela associação dos blocos restantes: Integrador, Relógio, Ganho, Soma e os de Função trigonométrica (seno e co-seno).

O bloco Relógio, obviamente um marcador temporal, em associação com um bloco Ganho, cuja intensidade equivale à frequiência de livre curso do PLL (wo), fornecem a componente intrínseca da fase integrada do Oscilador controlado por Voltagem (wo.t). Esta fase intrínseca somada (pelo bloco Soma) à fase integrada (pelo bloco Integrador) proporcional a intensidade do sinal de saída do filtro $\left(\theta_{o}(t)=K . u f(t)\right)$ compõem a fase do $\operatorname{VCO}\left(G_{2}(t)=w o \cdot t+G_{o}(t)\right)$. Recupera-se o sinal de saída do VCO pela avaliação do seno 
desta fase, tarefa executada pelo bloco Função seno. O emprego do bloco Função co-seno para a criação do sinal interno do PLL corresponde à estratégia, já mencionada, de atraso de $90^{\circ}$ da fase do PLL [BEST].

Como a malha é formada por uma associação de PLLs, todos com a mesma estrutura, diferindo apenas pelo valor de sua freqüência natural, que serve como parâmetro de entrada tanto no bloco da função transferência como no bloco ganho associado ao relógio, foi utilizado um programa [PIQUEIRA ET AL.] que sistematiza a montagem dos PLLs bem como da malha em estudo. Este programa monta, a partir da Matriz de Conexão, a malha correspondente (figura 8) e simula sua evolução.

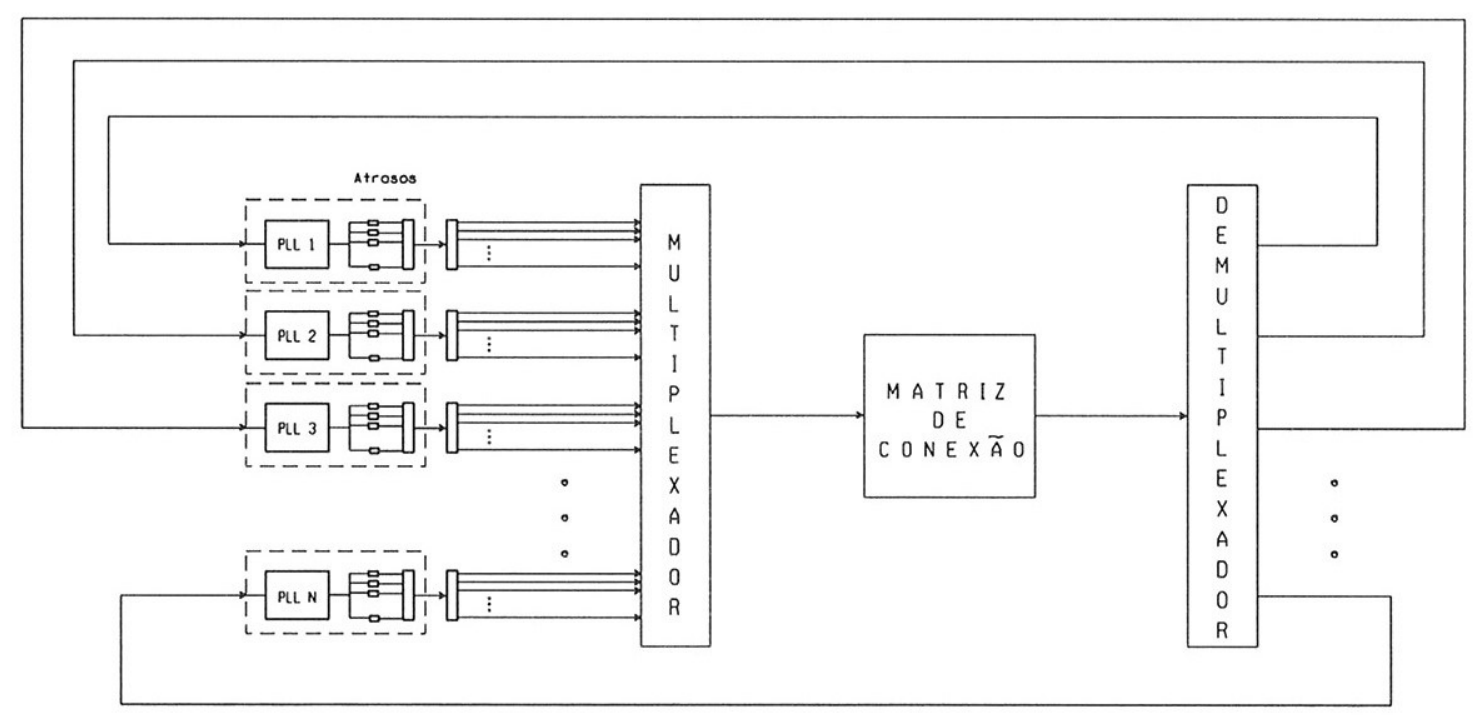

Figura 8: Diagrama esquemático da estruturação da malha de PLLs no programa utilizado nas simulações.

A montagem da malha pelo programa, inicia-se pela criação dos $N$ nós que compõe o sistema, onde cada nó é um PLL. A conexão entre os nós é regida pelo bloco função matemática designado como Matriz de Conexão. Em função deste bloco aceitar apenas um dado de entrada por avaliação, os sinais de todos os nós devem ser "multiplexados" antes de entrarem neste deste bloco. Esta multiplexação corresponde a um aumento na dimensão do dado de entrada, para que os sinais de saída de todos os nós sejam preservados. Da mesma 
maneira, o dado de saída do bloco Matriz de Conexão deve ser "demultiplexado", ou seja, os sinais de entrada dos $N$ diferentes nós devem ser separados e readequados à dimensionalidade de trabalho de cada nó - recuperação da dimensão do sinal. O programa também possibilita a inclusão de atrasos nas conexões existentes.

Como dados de entrada deste programa têm-se:

- a Matriz de Conexão, que é normalizada para que a somatória dos pesos das conexões que servem de sinais de entrada no detector de fase seja igual à unidade;

- o ganho dos PLLs, que por simplicidade é considerado o mesmo para todos os elementos da rede;

- a distribuição de freqüências, que é dada por um vetor de dimensão equivalente à ordem da malha $(N)$ e

- uma matriz de atraso, dada por uma matriz quadrada de dimensão igual a da Matriz de Conexão $(N \times N)$.

Resultam, destas simulações, as fases de cada um dos PLLs nos estados calculados pelo programa (figura 9). Nesta figura, as fases de cada um dos nós de uma malha são apresentadas em função do tempo de acompanhamento do sistema, ilustrando a resposta típica dos sistemas de interesse estudados. Apesar das fases serem definidas somente para alguns valores do tempo de acompanhamento, optou-se por apresentar os dados unindo os pontos que caracterizam fases sucessivas de um mesmo nó. 


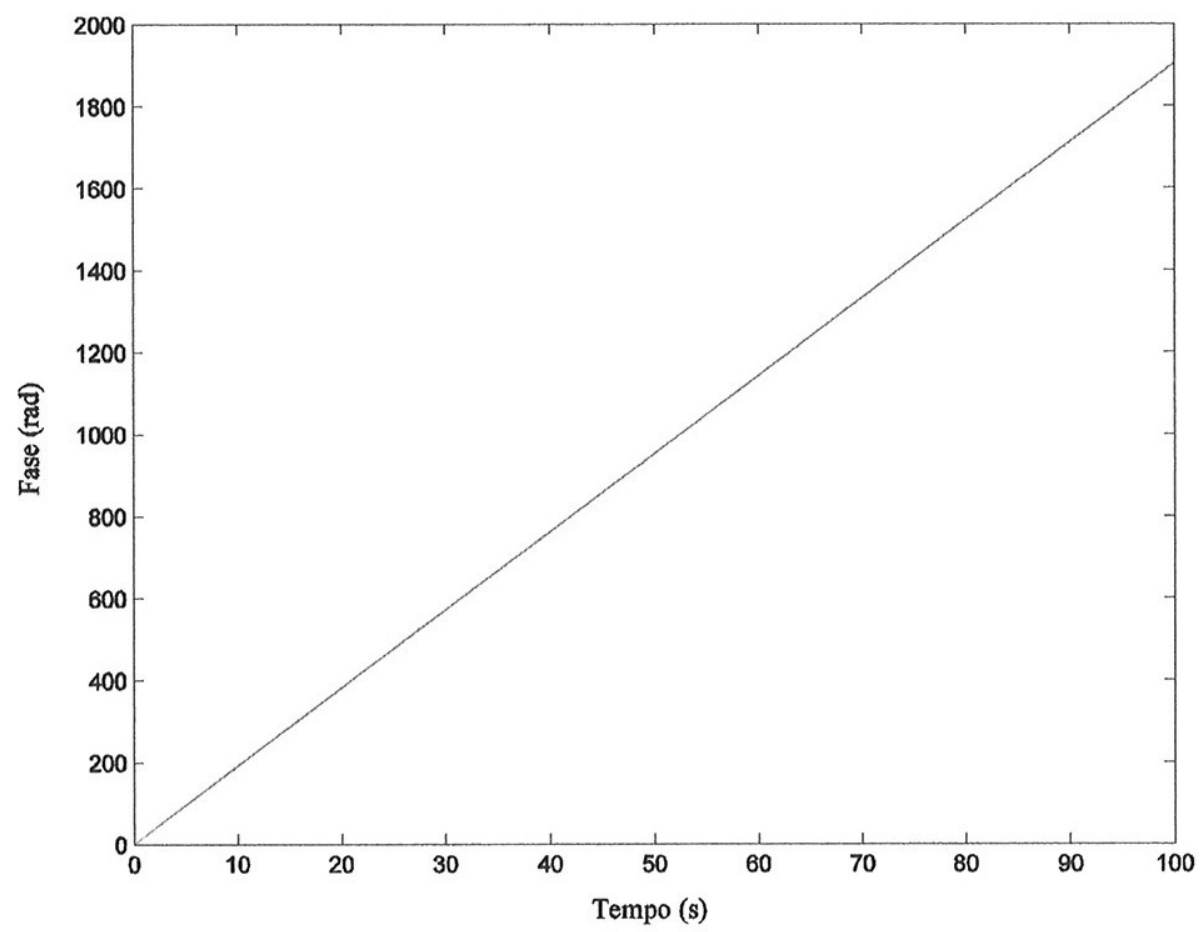

Figura 9: Fases dos nós para um caso estudado.

\section{Parâmetros Secundários}

Como recurso da plataforma, é possível controlar o passo de integração, o ganho de cada PLL, bem como o tempo de acompanhamento da evolução do sistema. Estes parâmetros apesar de não se encontrarem dentro do escopo deste trabalho, desempenham papel relevante na determinação do estado final dos sistemas simulados e no tempo de execução dos cálculos.

A dependência dos resultados das simulações e do custo no tempo de computação com os valores assumidos pelos parâmetros secundários demanda um cuidado adicional ao trabalho. A atribuição de valores a estes parâmetros obedeceu a três critérios básicos: representação de sistemas coerentes e redução no tempo de execução das simulações.

A interferência dos parâmetros secundários nos resultados obtidos deve-se tanto à metodologia de cálculo, no caso do passo de integração, como à determinação das 
condições de contorno que possibilite a obtenção do estado final em equilíbrio dinâmico, como é o caso do ganho.

\section{Passo de Integração (P.I.):}

Na modelagem de cada um dos sistemas dinâmicos estudados, os estados do sistema são caracterizados em intervalos finitos de tempo, tem-se, portanto, uma representação discreta de um processo contínuo. No procedimento de cálculo adotado, calcula-se especificamente a taxa de variação dos valores dos parâmetros do sistema. Os novos estados são determinados pelos estados imediatamente anteriores associados às estimativas de suas variações durante o intervalo considerado as quais são dadas pela composição da taxa de variação com o intervalo de tempo decorrente entre duas avaliações.

Conseqüentemente, apesar do programa se propor a simular sistemas determinísticos, pode haver uma divergência nos valores obtidos na simulação conforme o passo de integração adotado. A figura 10 apresenta, para 4 valores distintos do Passo de Integração (P.I.= 2,5 s; 0,25 s; 0,025 s e 0,0025 s), os resultados das simulações de um sistema composto por uma malha regular com 100 nós e grau médio 4 para. Apesar das simulações se referirem a um mesmo sistema, seus resultados são discordantes. Nos 2 gráficos superiores (P.I. $=2,5 \mathrm{~s}$ e $0,25 \mathrm{~s}$ onde são amostrados, respectivamente, 5 e 41 estados para cada nó no intervalo de acompanhamento de $10 \mathrm{~s}$ ), o sistema apresenta uma resposta divergente, com as fases assumindo valores discrepantes, evidenciados pelas escalas ( $10^{13}$ e 400 ). Já os 2 gráficos inferiores (P.I. $=0,025$ s e 0,0025 s onde são amostrados, respectivamente, 401 e 4001 estados para cada nó no intervalo de acompanhamento de $10 \mathrm{~s}$ ) os resultados são concordantes apresentando, além disso, um comportamento coerente (nós com mesma freqüência de oscilação).

Paralelamente, existe um comprometimento entre a eficiência no encaminhamento das simulações e o valor do passo de integração, pois com a diminuição do passo de integração o número de estados calculados deve aumentar para que o sistema seja determinado ao longo de um tempo de acompanhamento específico, concorrendo para o aumento no tempo de execução do programa. Por esta razão, adotou-se como passo de integração o maior valor, entre aqueles avaliados, para o qual não se evidenciaram efeitos desta natureza. 

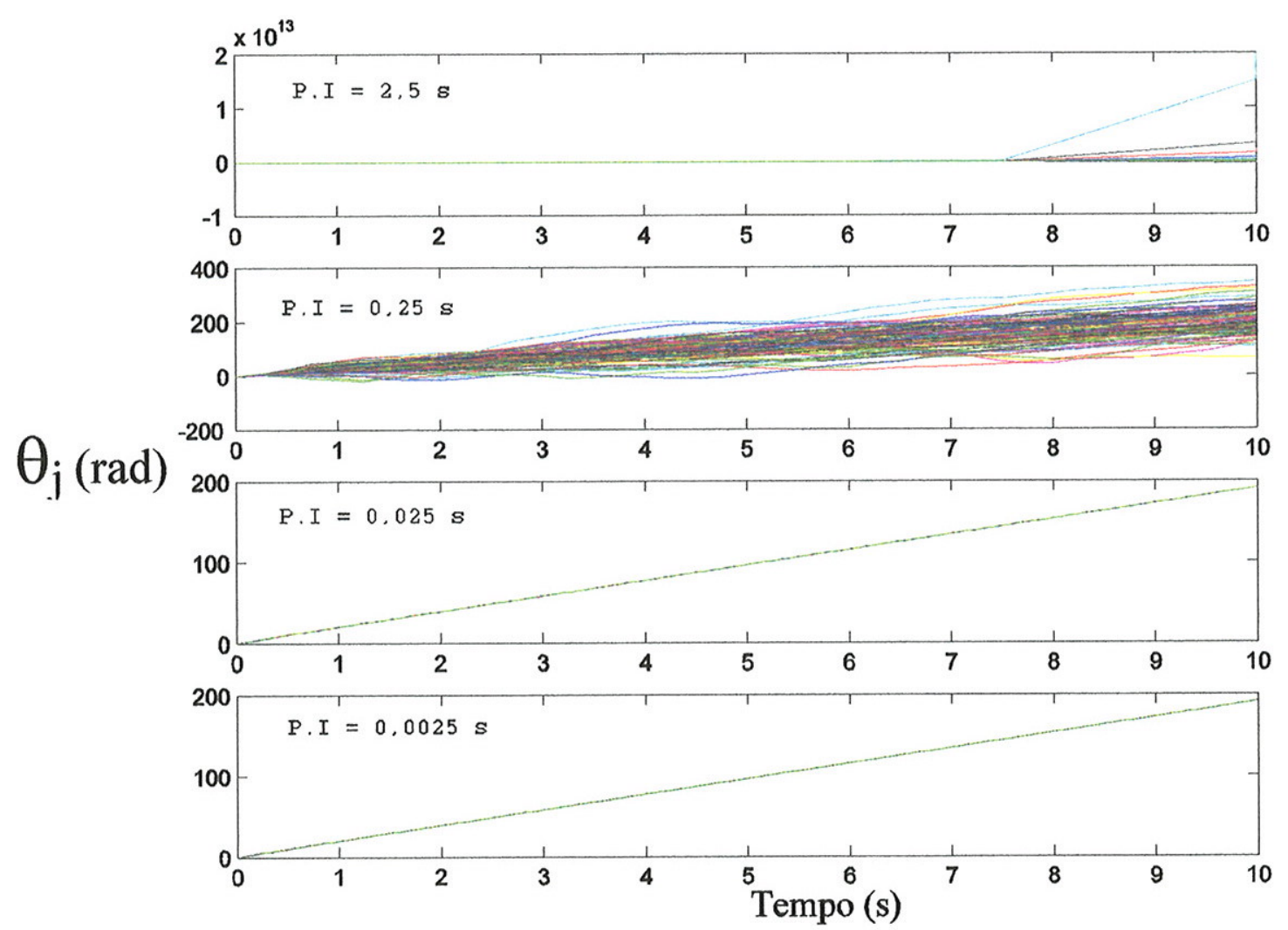

Figura 10: Fases dos nós de uma malha regular $(N=100, k=4)$ em função do tempo de acompanhamento (s) para diferentes passos de integração ( P.I. = 2,5 s; 0,25 s; 0,025 s e $0,0025 \mathrm{~s})$. Nestas simulações, o número de estados do sistema, excetuando-se o estado inicial ( $\mathrm{t}=0 \mathrm{~s}$ ), determinados para $10 \mathrm{~s}$ de tempo de acompanhamento foram, respectivamente, de 4, 40, 400 e 4000 .

O passo de integração de $0,025 \mathrm{~s}$, correspondendo à caracterização de 40 estados por segundo, foi utilizado em todas as simulações cujos resultados são doravante apresentados.

Ganho $(\mathrm{G})$ :

Ao contrário do passo de integração, o ganho representa uma característica inerente ao sistema analisado e não à metodologia de cálculo. Ele está associado à intensidade de acoplamento dos osciladores e, portanto, seria de se esperar, que com o seu aumento, a capacidade de sincronização do sistema aumentasse. Contudo, para um sistema composto 
por PLLs obedecendo uma determinada distribuição de freqüências naturais, existe um intervalo de valores de ganho para o qual se observa a sincronização do sistema.

A figura 11 ilustra a dependência da manifestação do comportamento coerente do sistema com o valor do ganho. Nesta figura são apresentados 4 gráficos, cada qual com um valor do ganho diferente, da evolução das fases dos nós de uma malha regular $(N=100$, $k=4)$ ao longo de $100 \mathrm{~s}$.

A apresentação destes resultados, para sistemas com valores incrementais do ganho (seqüencialmente, $\mathrm{G}=5 \mathrm{~V} / \mathrm{rad} . \mathrm{s}, 50 \mathrm{~V} / \mathrm{rad} . \mathrm{s}, 140 \mathrm{~V} / \mathrm{rad} . \mathrm{s}$ e $150 \mathrm{~V} / \mathrm{rad} . \mathrm{s}$ ), visa caracterizar a faixa do ganho para a qual a coerência é manifestada pelo sistema.

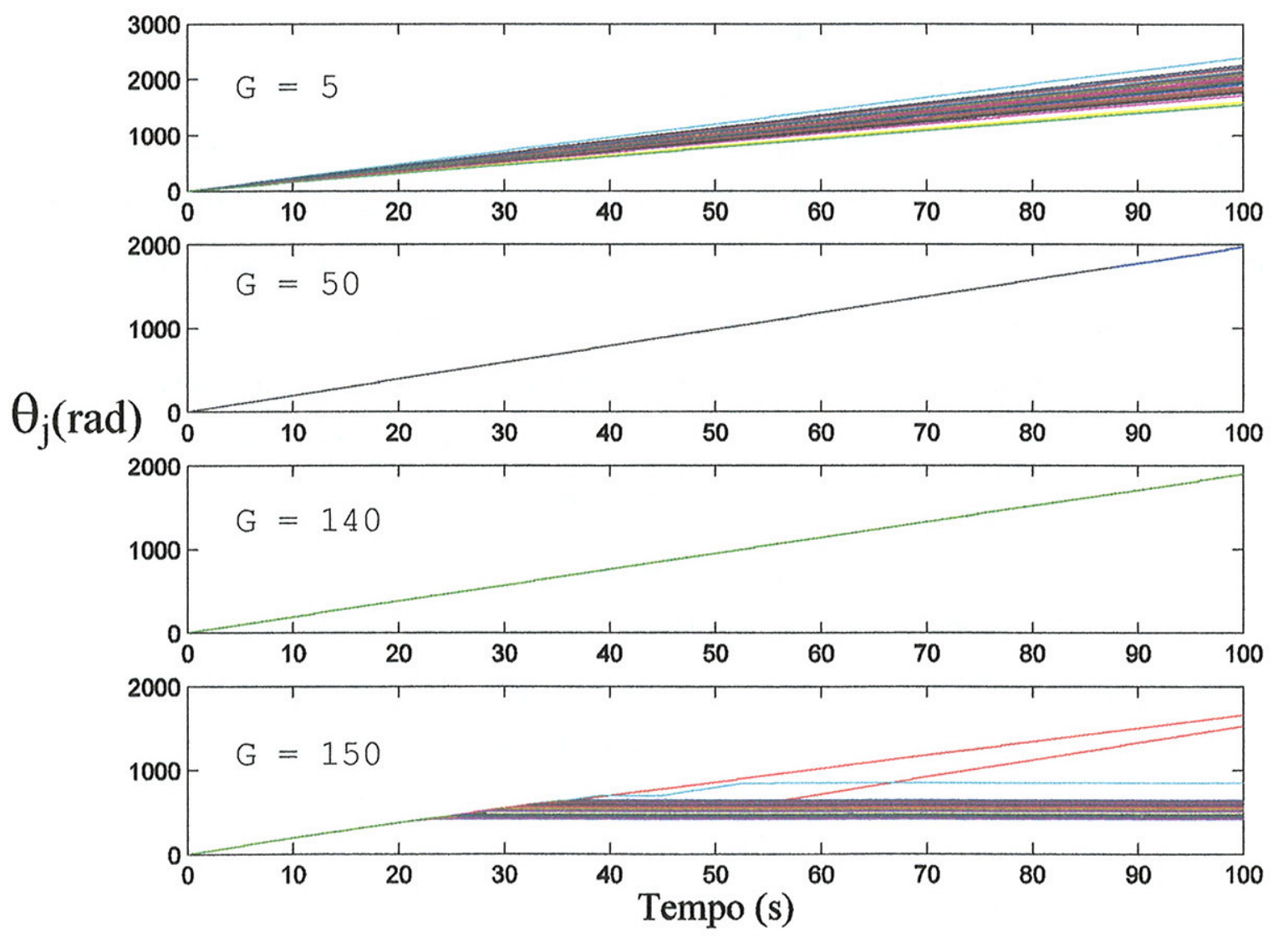

Figura 11: Fase dos nós $(\theta j)$ de uma malha regular $(N=100, k=4)$ em função do tempo de acompanhamento do sistema, para 4 valores diferentes de ganho ( $G=5$ V/rad.s, 50 V/rad.s, 140 V/rad.s e 150 V/rad.s). 
Observa-se nos gráficos das extremidades superior e inferior, respectivamente, correspondentes a sistemas com ganhos de $5 \mathrm{~V} / \mathrm{rad} . \mathrm{s} 150 \mathrm{~V} / \mathrm{rad} . \mathrm{s}$, que seus nós apresentam taxas de variação de fase diferentes, o que corresponde a nós oscilando em frequiências diferentes. Em contrapartida, os gráficos centrais $(\mathrm{G}=50 \mathrm{~V} / \mathrm{rad} . \mathrm{s}$ e $140 \mathrm{~V} / \mathrm{rad} . \mathrm{s})$ apresentam comportamento coerente (nós com mesma freqüência de oscilação).

Simulações para sistemas com valores de ganho intermediários também apresentam coerência.

Verifica-se que, tanto para o passo de integração como para o ganho, existe um valor limiar acima do qual o sistema não converge para um padrão de comportamento coerente. No caso do ganho, esta limitação estende-se também a seu valor mínimo, caracterizando uma faixa de operação adequada aos propósitos deste estudo.

Semelhantemente ao passo de integração, existe um comprometimento entre o valor de ganho adotado nas simulações e a eficiência, utilizada como sinônimo de rapidez e representatividade, na obtenção dos resultados. Todavia, esta dependência não representa um efeito espúrio derivado do processo de cálculo. Sua manifestação está na resposta mais rápida do sistema, ou seja, o sistema atinge o seu estado de equilíbrio mais rapidamente (figura apêndice), possibilitando a redução do tempo de acompanhamento do sistema e, conseqüentemente, do tempo de execução do programa.

Objetivando a aceleração no procedimento de obtenção de dados, optou-se por utilizar nas simulações, aqui apresentadas o valor de $140 \mathrm{~V} / \mathrm{rad} . \mathrm{s}$, correspondente ao valor máximo de ganho avaliado para o qual o sistema manifestou coerência.

Além da diminuição no tempo transiente do sistema, o aumento do ganho também influencia na redução dos valores da freqüência de coerência (figuras A1 e A2 do apêndice) [PIQUEIRA ET AL.] e na amplitude do perfil diferença de fase (figura A3).

\section{Parâmetros principais}

Apesar do programa fornecer, como dado primário de saída, as fases dos nós em determinados momentos, foram usados como indicadores de resposta do sistema, os seguintes parâmetros dinâmicos: a Diferença de Fase $(\Phi)$, a Freqüência $(W)$ e o Tempo de Sincronização (T.S.). A opção pela adoção destes parâmetros como caracterizadores dos 
sistemas em estudo justifica-se pela estabilidade apresentada por estes parâmetros no estado coerente. Ao contrário das fases dos nós, cujos crescem continuamente com o tempo (figura 9), os parâmetros principais $\Phi$ e $W$ assumem valores estáveis a partir do tempo T.S. (figuras 12 e 13).

A diferença de fase de um nó $j$ qualquer $(\Phi j)$ é obtida pela diferença entre as fases do PLL $j$ num determinado tempo $\theta j(t)$ e de um PLL de referência, $r$, no mesmo instante $\theta r$ $(t)$.

$$
\Phi j(t)=\theta j(t)-\theta r(t)
$$

e que é calculada para todos os nós da malha e onde $\Phi r \equiv 0$.

A figura 12 mostra o comportamento do parâmetro $\Phi j(t)$ para 10 nós regularmente distribuídos ao longo de uma malha regular $(N=100$ e $k=4)$. Observa-se que cada $\Phi j$ oscila em torno de um valor que, num determinado intervalo com tempo de acompanhamento do sistema menor que $10 \mathrm{~s}$, altera-se e que a seguir estabiliza-se. Este comportamento é representativo de todos os $\Phi j$, com $j \neq r$. A exposição de apenas 10 dos 100 nós da malha deve-se à busca da melhor visualização da resposta deste parâmetro com o tempo.

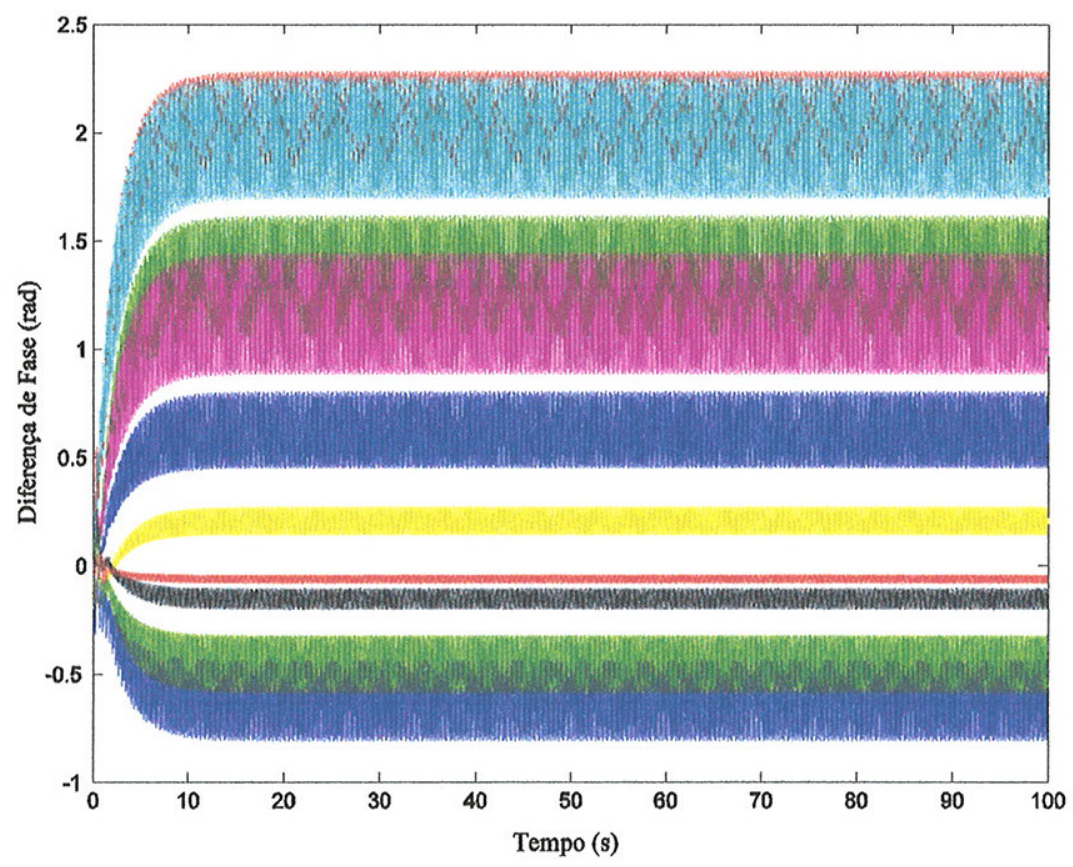

Figura 12: Evolução da diferença de fase para diferentes nós de um sistema. 
A frequiência de oscilação $(W j)$ de um nó qualquer, $j$, é calculada pela razão da diferença entre as fases do nó $j$ em instantes (estados) sucessivos $[\Delta \sigma j(t)=\theta j(t+\Delta t)-6 j(t)]$ e o passo de integração $($ P.I. $=\Delta \mathrm{t})$.

$$
W j(t)=\frac{\Delta G j(t)}{\Delta t}
$$

A figura 13 mostra o comportamento das freqüências calculadas para os mesmos nós do sistema, cujas diferenças de fase foram apresentadas na figura 12. Verifica-se que tal qual a diferença de fase a freqüência de oscilação de cada nó oscila em torno um valor que, num primeiro instante, altera-se e posteriormente estabiliza-se. Os valores iniciais de $W j$ situam-se próximos a $20 \mathrm{rad} / \mathrm{s}$, devido aos valores atribuídos às freqüências naturais de livre curso dos PLLs obedecerem uma distribuição normal com valor médio próximo a este valor.

Existem contudo algumas diferenças básicas entre os comportamentos de $\Phi j$ e $W j$. Enquanto cada $\Phi j$ oscila em torno de um valor que parte de zero para estabilizar-se num valor diferente para cada nó $j$, cada $W j$ oscila em torno de um valor cujo limite é coincidente para todo $j$. Este comportamento já é esperado, pela própria dinâmica do PLL que consiste na capacidade do VCO gerar um sinal na mesma freqüência do sinal externo a partir da alteração, controlada pela diferença de fase entre estes sinais, da sua freqüência de livre curso. A segunda diferença concerne à duração do estado transiente do sistema. A estabilização dos valores em torno dos quais os Wjs oscilam parece ocorrer antes da estabilização dos correspondentes $\Phi j$ s. A aparente reposta mais rápida da freqüência devese à amplitude das oscilações associada à sobreposição de oscilações sem sincronismo. 


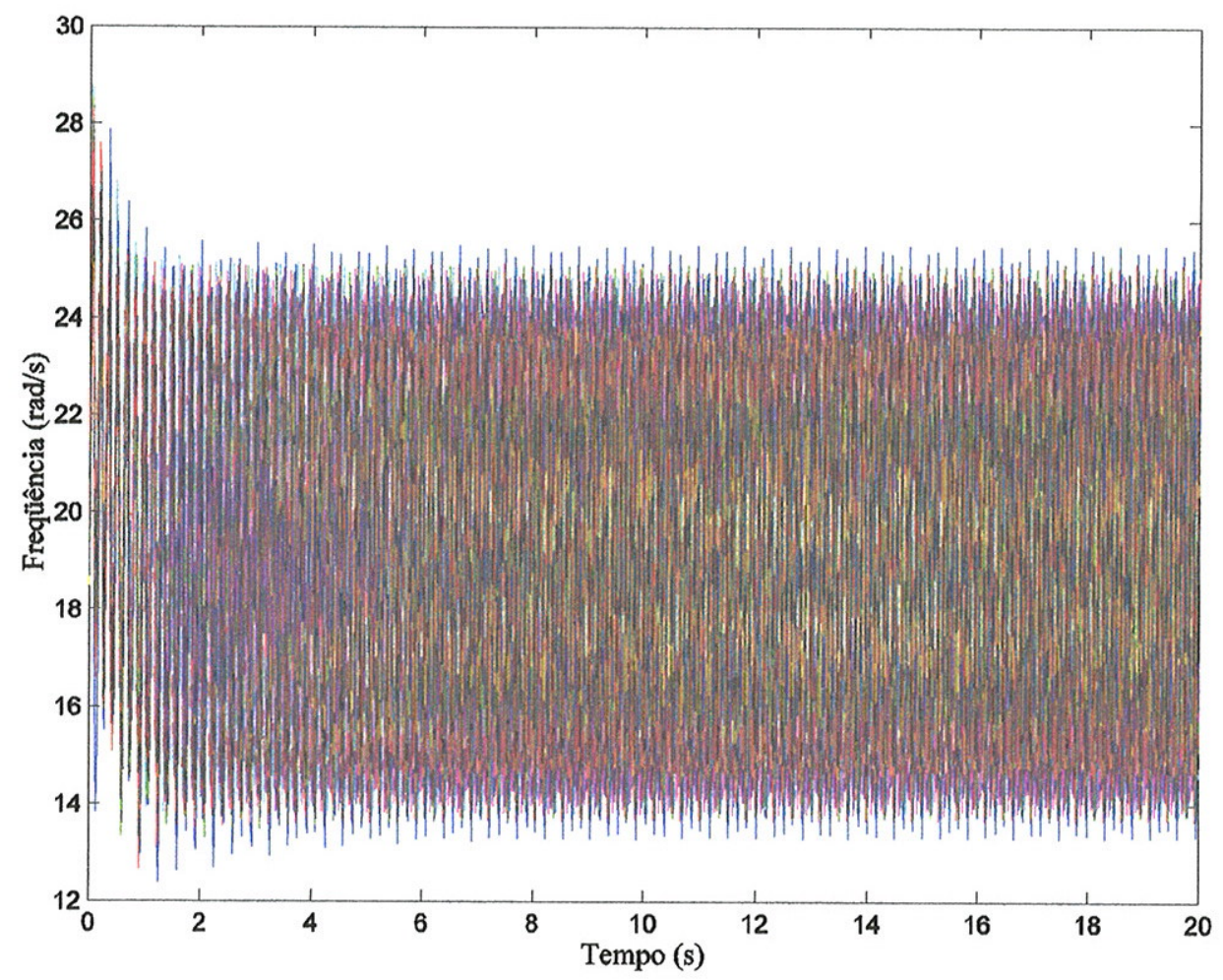

Figura 13: Evolução da freqüência de 10 nós regularmente dispersos ao longo de uma malha regular $(N=100, k=4)$.

Uma questão que se levanta a partir da análise das figuras 12 e 13 refere-se à "oscilação" dos valores das freqüências e das diferenças de fase. Observa-se que o sistema não sincroniza, mas sim, estabiliza-se em torno de certos valores. Este efeito, já relatado por PIQUEIRA E MONTEIRO, corresponde à presença da componente do segundo harmônico (figura 14) e deve-se, em parte, às condições iniciais adotadas na simulação do sistema $(\theta j=0$, para todos os $j \mathrm{~s})$.

A apresentação dos sinais e da freqüência de 5 nós deve-se à intenção de evidenciar que a presença do termo de freqüência dupla não se restringe ao sinal de apenas um PLL, mas se estende a todos os PLLs da malha. A escolha dos PLLs representados, os 5 dispostos seqüencialmente ao longo do anel que caracteriza uma malha regular de dimensão 1, busca facilitar a visualização com a apresentação de oscilações sincronizadas. 

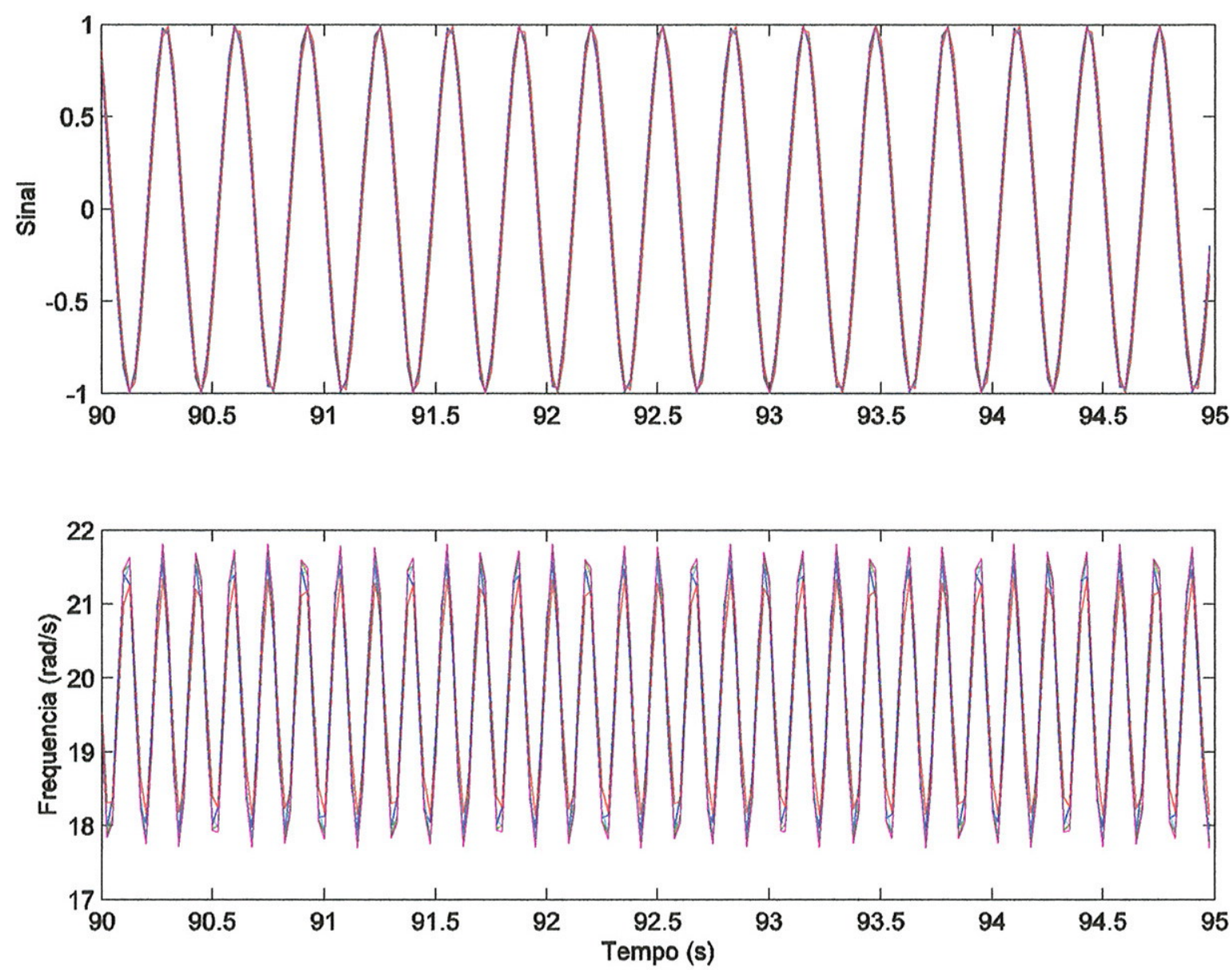

Figura 14: Sinais e freqüências 5 PLLs de uma malha de ordem 100 e grau 4 em seu estado de equilíbrio.

Com a exposição dos sinais e freqüências mais de 1 PLL na figura 14, procura-se ratificar a extensão da ocorrência de tal fenômeno a todos os PLLs da malha. A limitação quanto ao número de PLLs representados, deve-se a inexistência de sincronismo entre os PLLs da malha deste sistema, o que prejudicaria a visualização da componente do segundo harmônico caso todos os PLLs fossem representados.

Em função do sistema não atingir a coerência, mas uma estabilidade, os valores destes parâmetros $(\Phi j$ e $W j)$ oscilam e, portanto, uma média temporal é calculada para representar seus valores na estabilidade.

As figuras 15 e 16 ilustram a avaliação feita para os resultados obtidos para a simulação de um sistema constituído por uma malha regular com 100 nós $(k=4)$. Nestas figuras são graficados os valores médios dos parâmetros considerados para cada um dos 
nós da malha, tomando-se distintos intervalos na avaliação: 2000, 1999, 1995, 1990, 1900 e 1000 estados, correspondendo a tomada da média para os últimos $25-50$ segundos de simulação. A escolha destes intervalos busca avaliar as alterações verificadas nos valores médios dos parâmetros de interesse frente a diferenças no tamanho do espaço amostral que variam de 1 estado, correspondendo a uma redução de $0,05 \%$, a 1000 estados, equivalente à redução de $50 \%$.
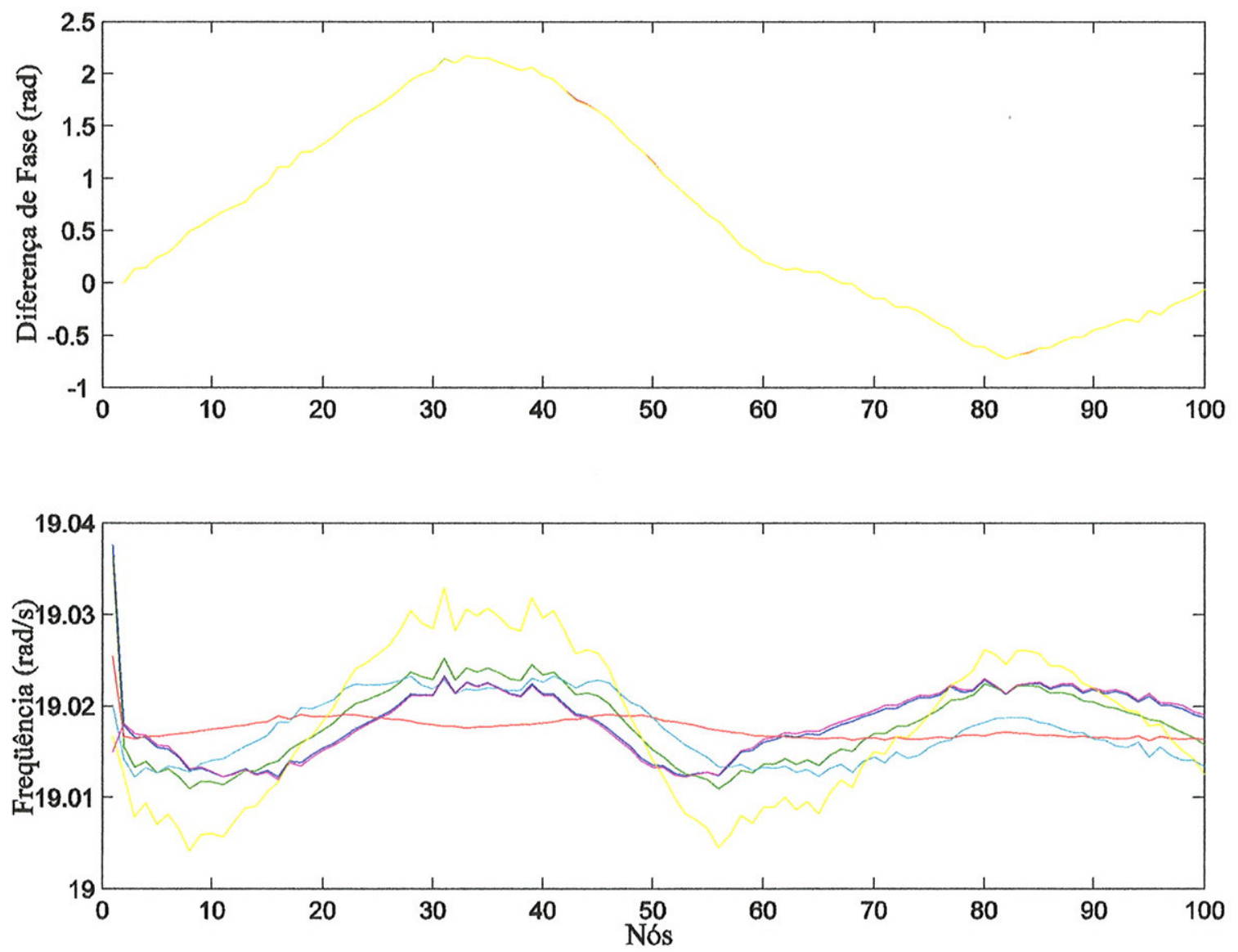

Figura 15: superior (a): valores das médias da diferença de fase calculadas para cada um dos ( $N$-1) nós a partir das médias de diferentes tamanhos de amostragem; inferior(b) Valores das médias da freqüência, calculadas para cada um dos $N$ para os mesmos intervalos utilizados em (a): 2000 estados (50 s) em azul escuro, $1999 \mathrm{em}$ verde, $1995 \mathrm{em}$ vermelho, $1990 \mathrm{em}$ azul claro, $1900 \mathrm{em}$ magenta e 1000 (25 s) em amarelo. 
Observam-se alterações de até $5.10^{-4}(\mathrm{rad})$ para $\Phi_{j}$ e de $2.10^{-2}(\mathrm{rad} / \mathrm{s})$ para $W j$. Uma avaliação da sensibilidade do valor médio destes parâmetros frente ao intervalo considerado no cômputo da média sugere a apresentação, por parte da freqüência, de uma maior sensibilidade, quando comparada com a diferença de fase. Contudo, os efeitos desta sensibilidade são mínimos na análise conduzida neste trabalho, desde que se assegure que a avaliação não se estenda além do intervalo em que o sistema se encontra no estado de equilíbrio final.
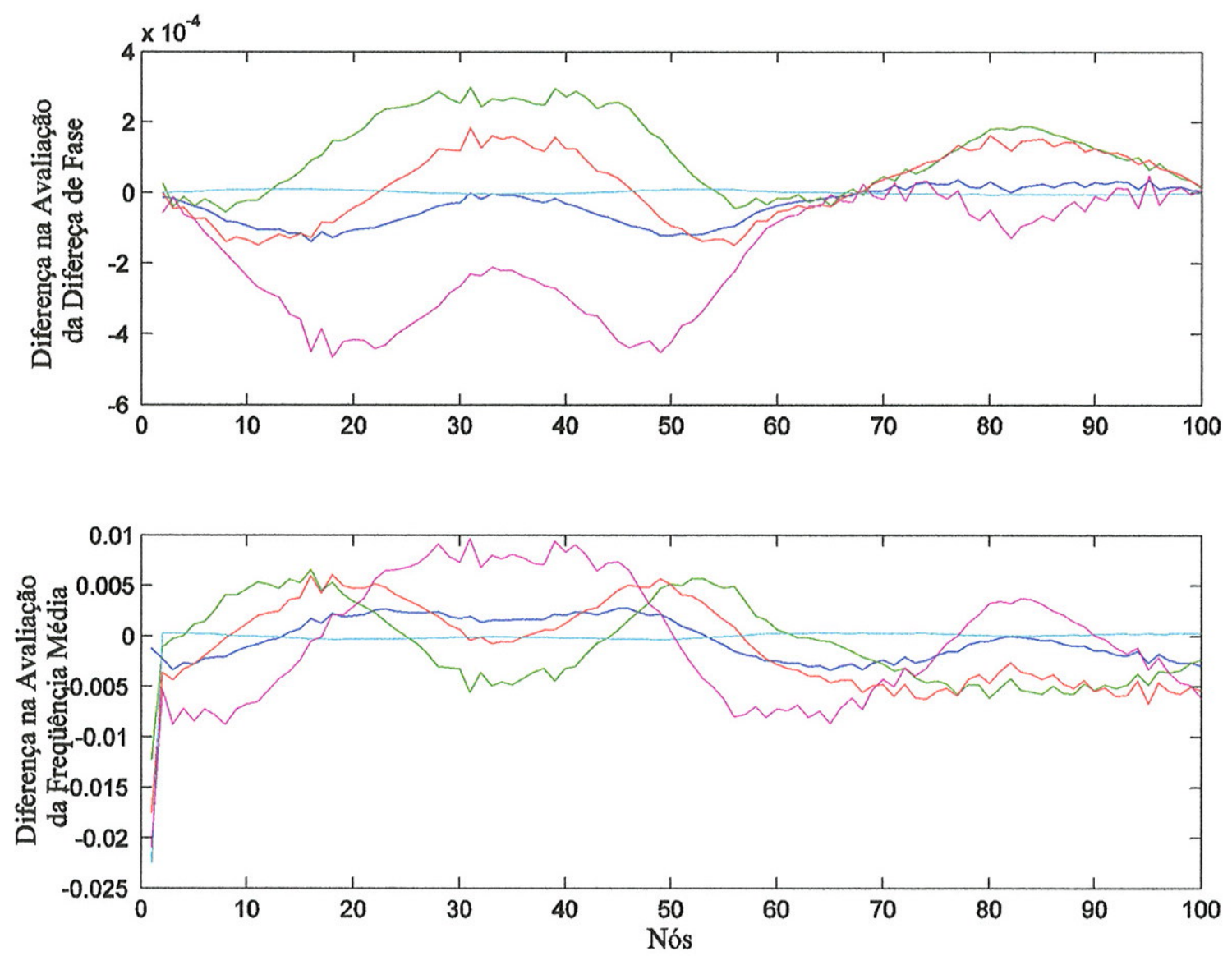

Figura 16: Diferença entre os valores das médias calculadas e apresentadas nas figuras 10 (a) e 10 (b), adotando-se as médias obtidas para o maior intervalo como referência; 1999 estados em azul escuro, $1995 \mathrm{em}$ verde, $1990 \mathrm{em}$ vermelho, $1900 \mathrm{em}$ azul claro e 1000 (25 s) em magenta. 
O tempo de sincronização (T.S.) é um parâmetro que visa quantificar a duração do período transiente do sistema. Devido à convergência do sistema para um estado coerente, com o sistema apresentando um freqüência de oscilação cujo valor oscila, acresce-se uma dificuldade na caracterização do fim do estado transiente. Buscando uma melhor caracterização do início do estado coerente, T.S. é obtido pela redução de estimadores que quantificam as alterações nas $\Phi j$ s dos nós de uma malha.

Para a determinação do tempo de sincronização, adota-se o seguinte procedimento:

- as diferenças de fase correspondentes à cada nó são "zeradas" pelo valor médio de retenção da diferença de fase (Subtração das diferenças de fase)

$$
N \Phi_{j}(t)=\Phi_{j}(t)-\frac{1}{m} \cdot \sum_{\substack{n=1 \\ t^{\prime}>>0}}^{m} \Phi_{j}\left(t^{\prime}+n \cdot P . I .\right)
$$

onde $m$ é o número de estados considerados da avaliação do valor médio do estado coerente e que, conforme explicado, assume um valor da ordem de 1000 (figura $17 \mathrm{~b}$ ).

- os valores normalizados da diferença de fase são somadas por um período para a redução do efeito de oscilação (Soma por um período)

$$
S N \Phi_{j}(t)=\frac{1}{T} \cdot \sum_{n=1}^{T} N \Phi_{j}(t+n \cdot P . I .)
$$

onde $T$ é o número de estados considerados em um período (figura 17 c) 

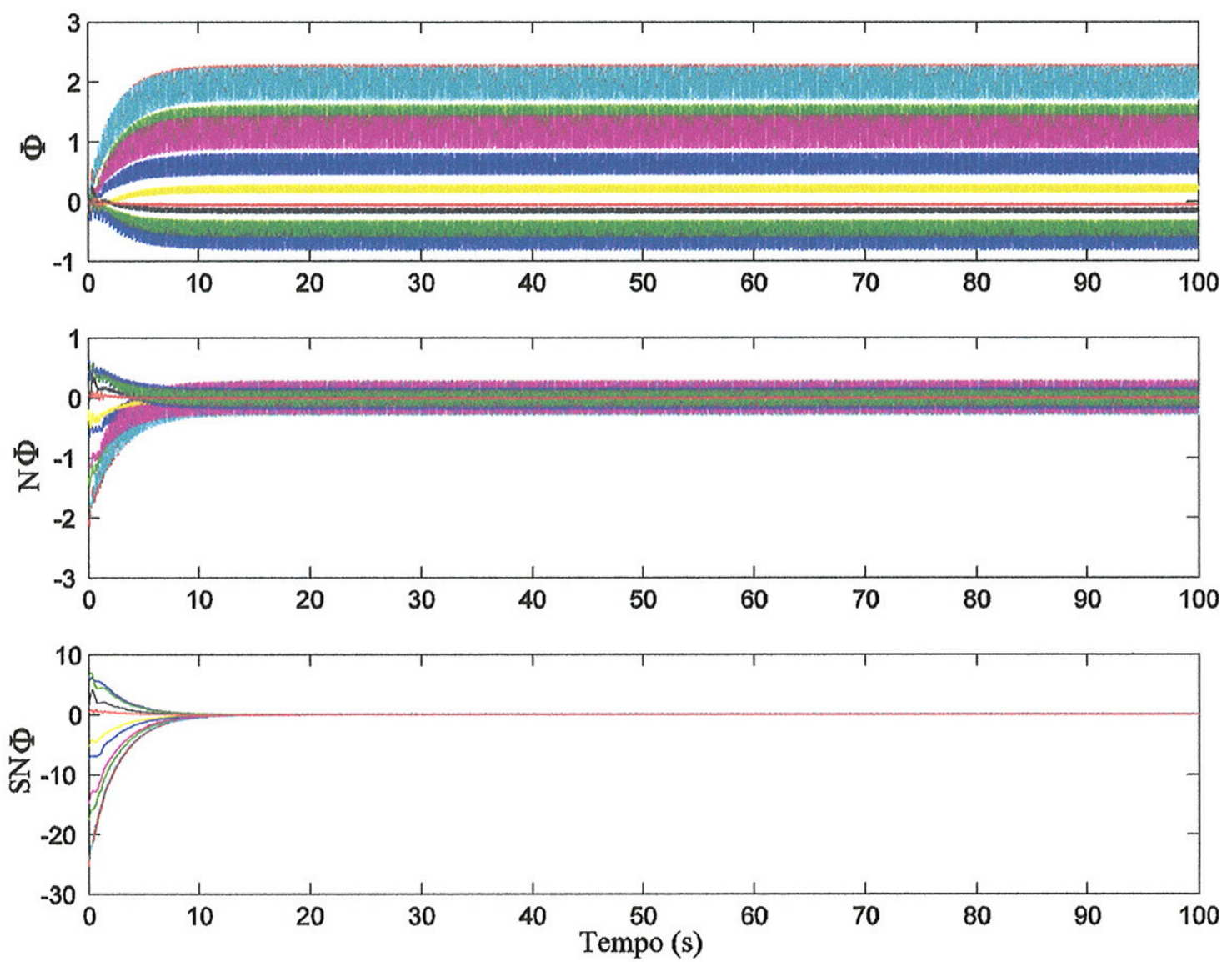

Figura 17: llustração dos efeitos da manipulação dos dados efetuada na avaliação de T.S. superior (a): diferença de fase em função do tempo de acompanhamento da simulação para 10 nós de uma malha de ordem 100 e grau 4 (reprodução da figura 7); central (b): $N \Phi$ e inferior (c): $S N \Phi$.

A figura 18 constitui-se na reprodução dos dados apresentados na figura 17 , mas para um intervalo correspondente ao tempo de acompanhamento que se estende de 5 a $30 \mathrm{~s}$. Verifica-se, nesta figura, que $S N \Phi j$ constitui-se num parâmetro mais sensível na percepção da estabilização(convergência) do sistema. 

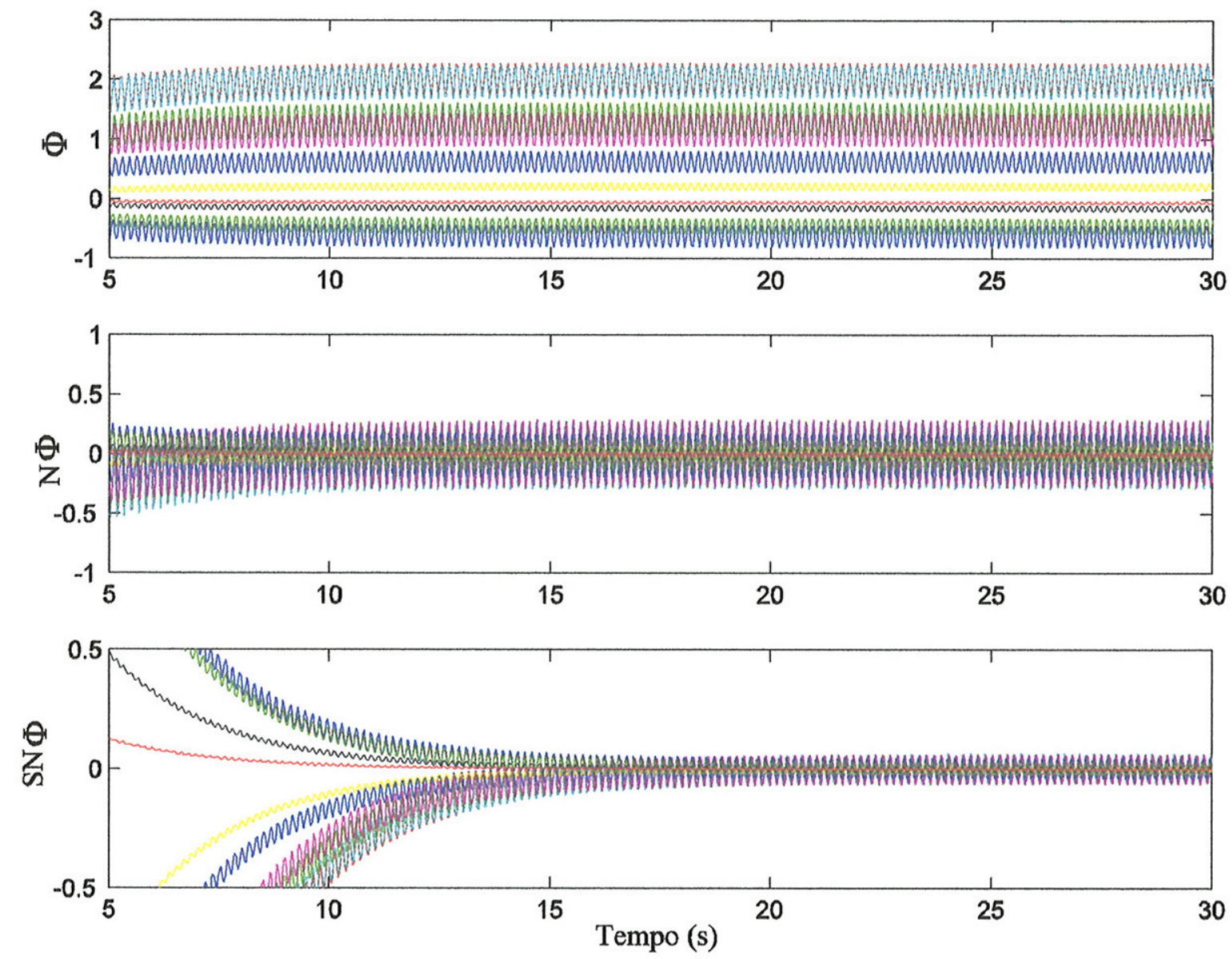

Figura 18: Ampliação da figura $17(a, b, c)$ : realçado a diferença no comportamento dos parâmetros $\Phi$, NФ e SNФ nos instantes próximos à estabilização do sistema.

Anteriormente à quantificação de T.S. ainda empregam-se dois outros estimadores:

E1: Soma dos valores absolutos de $\mathrm{SN} \Phi \mathrm{j}(\mathrm{t})$

$$
E 1(t)=\sum_{j}\left|S N \Phi_{j}(t)\right| \mathrm{e}
$$

E2: Soma dos quadrados das diferenças entre $\mathrm{SN} \Phi \mathrm{j}(\mathrm{t})$ e $\mathrm{SN} \Phi \mathrm{j}(\mathrm{t}>>0)$

$$
E 2(t)=\sum_{j}\left[S N \Phi_{j}(t)-S N \Phi_{j}(t>>0)\right]^{2} .
$$

Na figura 19 ilustra-se o comportamento destes dois estimadores para o caso apresentado nas figuras $17 \mathrm{e} 18$. 


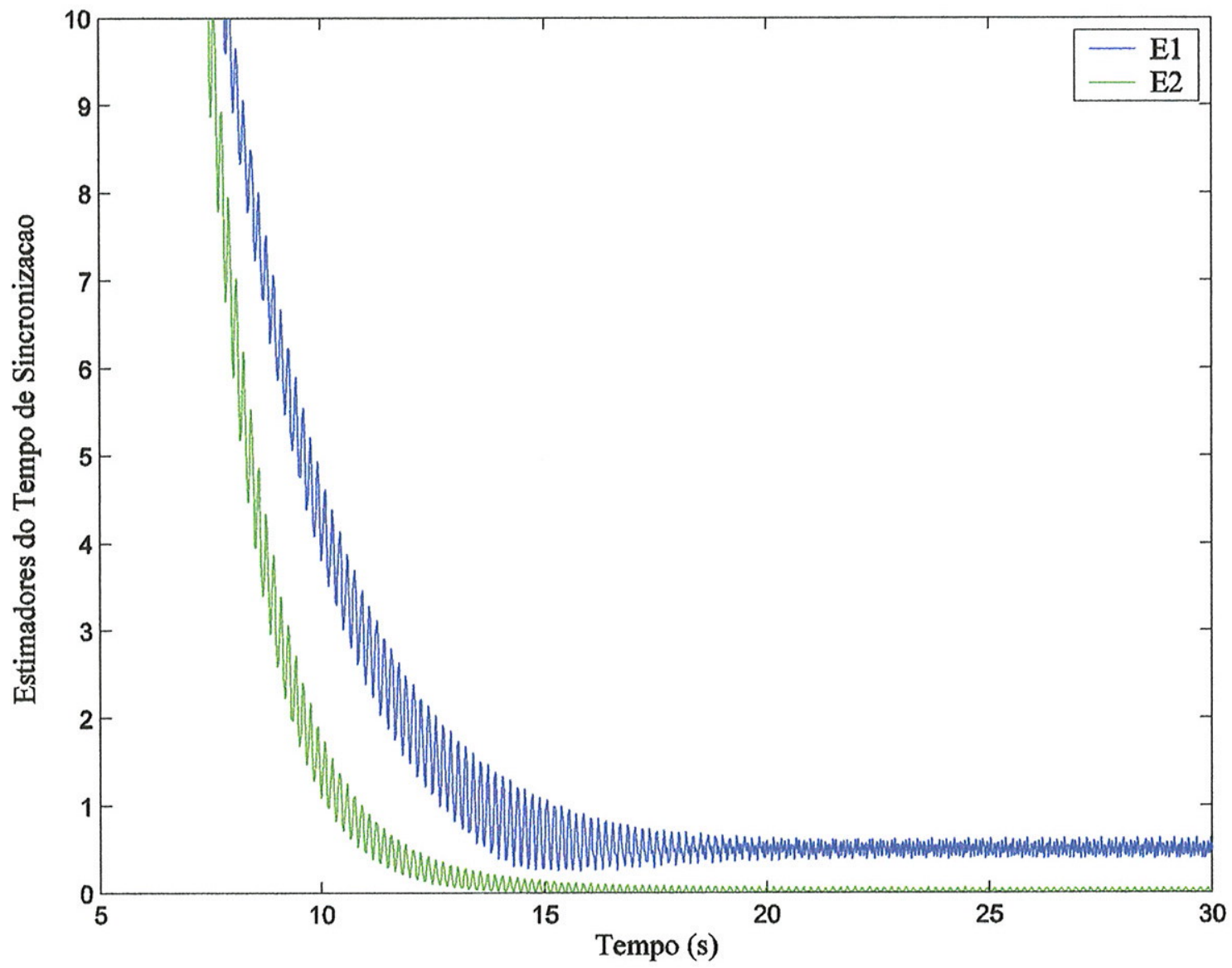

Figura 19: Evolução dos valores de $E 1$ e E2 ao longo do tempo de acompanhamento de evolução do sistema composto por uma malha regular $(N=100, k=4)$.

Para ambos estimadores (E1 e E2), T.S. é quantificado com o valor do instante em que os estimadores assumem valor igual ou inferior à média de seus valores no estado de equilíbrio (estado de retenção). 


\section{Redução de dados}

Definidos os parâmetros principais para a caracterização dos estados de retenção (equilíbrio) dos sistemas estudados neste trabalho, verifica-se que, para sistemas de mesma ordem $(N)$ e mesmo grau $(k)$, existe uma perda do padrão de perfil de diferenças de fase com o aumento da irregularidade de malha, onde o perfil de diferença de fase é o conjunto dos valores médios de retenção do parâmetro $\Phi$ de todos os nós, com ordenação definida pela malha regular.

A figura 20 apresenta os perfis de diferença de fase para malhas de 100 nós e grau

médio 4 , com diversos graus de irregularidade ( $p=0 ; 0,001 ; 0,01,0,1$ e 1$)$. Verifica-se que o perfil definido para a malha regular $(p=0)$ vai se alterando com o aumento na irregularidade da malha, porém malhas com graus de regularidade próximos, apresentam perfis parecidos.

Como estratégia para quantificar os diferentes perfis de diferença de fase, foram utilizados o valor médio de cada perfil $(m \Phi)$ e o desvio-padrão associado $(\sigma \Phi)$. A mesma estratégia foi utilizada na caracterização da frequiência de oscilação do sistema no estado de equilíbrio, concorrendo para definição do valor médio da frequiência de oscilação do estado de equilíbrio $(m W)$ e do seu desvio padrão $(\sigma W)$. Este tratamento têm apenas o intuito de possibilitar a classificação do estado final a partir da quantificação destes parâmetros de estado; a dinâmica do sistema continua a apresentar a riqueza de comportamento ilustrada ao longo do texto. 

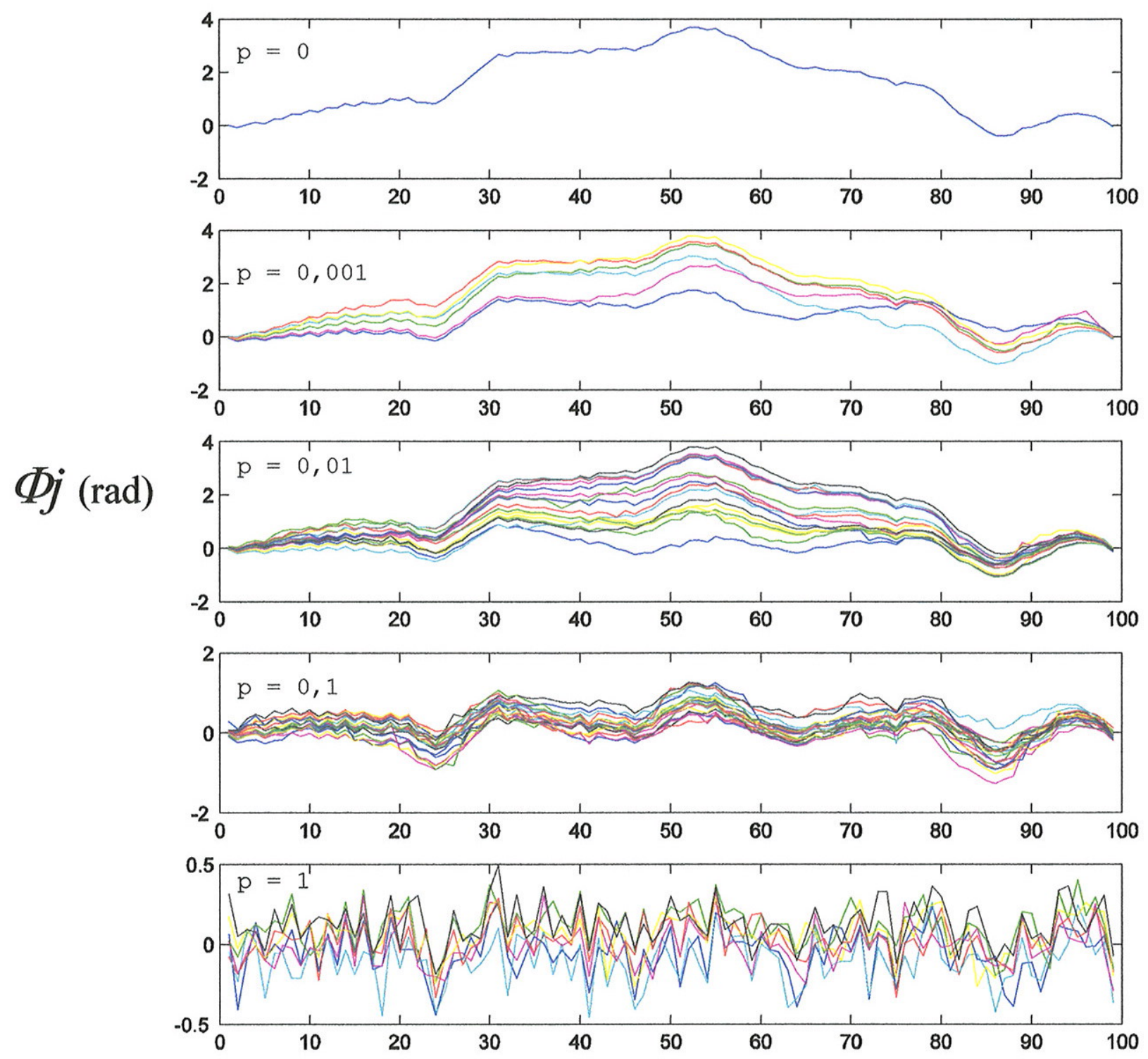

Nós ( j )

Figura 20: Perfis da diferença de fase para malhas com probabilidades crescentes de alteração das conexões da malha regular (de cima para baixo: $p=0,10^{-3}, 10^{-2}, 10^{-1}$ e 1). 


\section{Resultados}

Apresentam-se nas figuras a seguir os resultados obtidos ao longo do trabalho.

Todos os dados resultam de simulações executadas adotando-se os parâmetros de cálculo com os seguintes valores: passo de integração (P.I.) constante e equivalente a 0,025 s; ganho de $140 \mathrm{~V} / \mathrm{rad} . \mathrm{s}$; fases iniciais e atrasos zerados e freqüências naturais obedecendo a uma distribuição normal com valor médio próximo a $20 \mathrm{rad} / \mathrm{s}$ com desviopadrão da ordem de $10 \%$ (2 rad/s). Para a obtenção da distribuição normal de frequiências naturais empregou-se uma função interna ao MATLAB que gera um conjunto de valores que, dentro de certos limites estatísticos, tem seu valor médio e desvio-padrão controlados.

As figuras 21 a 23 são relativas a dois conjuntos de simulações que têm as mesmas malhas (uma regular e 49 irregulares, todas com 100 nós e grau médio 4) e a mesma distribuição de freqüências naturais com média 19,87 rad/s e desvio-padrão de 1,73 rad/s. Para a obtenção da distribuição normal de freqüências naturais empregou-se uma função interna ao MATLAB que gera um conjunto de valores que, dentro de certos limites estatísticos, tem seu valor médio e desvio-padrão controlados (valor médio próximo a 20 com desvio padrão próximo a 2). Optou-se, porém, por apresentar os valores que caracterizam a distribuição utilizada nas simulações.

A diferença entre os dois conjuntos de simulações decorre do procedimento adotado na atribuição da freqüência de cada nó. Obedecendo ao mesmo ordenamento na especificação da distribuição de freqüências, atribuiu-se a um nó $i$ (associado a um sítio $i$ da malha regular) do primeiro conjunto o mesmo valor da frequiência atribuído ao nó correspondente ao sítio diametralmente oposto (segundo a o ordenamento adotado na malha regular) do segundo conjunto. Ou seja, para o caso específico de uma malha de ordem 100,

$$
\begin{array}{ll}
f 1_{i}=f 2_{i+50,} & \mathrm{p} / i=1 . .50 e \\
f 1_{i}=f 2_{i-50}, & \mathrm{p} / i=51 . .100,
\end{array}
$$


onde $f 1 i$ e $f 2 j$ são as freqüências de livre curso atribuídas, respectivamente, ao nó $i$ do primeiro conjunto de simulações e ao nó $j$ do segundo conjunto.

Estas simulações correspondem ao estudo de um mesmo sistema original, adotandose a malha regular como sistema referência no estudo da influência da regularidade da malha na determinação dos parâmetros dinâmicos do estado de equilíbrio (estado coerente), pois os sistemas-referência de cada conjunto simulado diferem entre si pela simples rotação na designação das freqüências de cada nó. Assim, cada malha irregular de um conjunto equivale a uma nova configuração do sistema do outro conjunto, preservando-se porém os parâmetros $L$ (Comprimento Característico) e $\gamma$ (Clickshness).
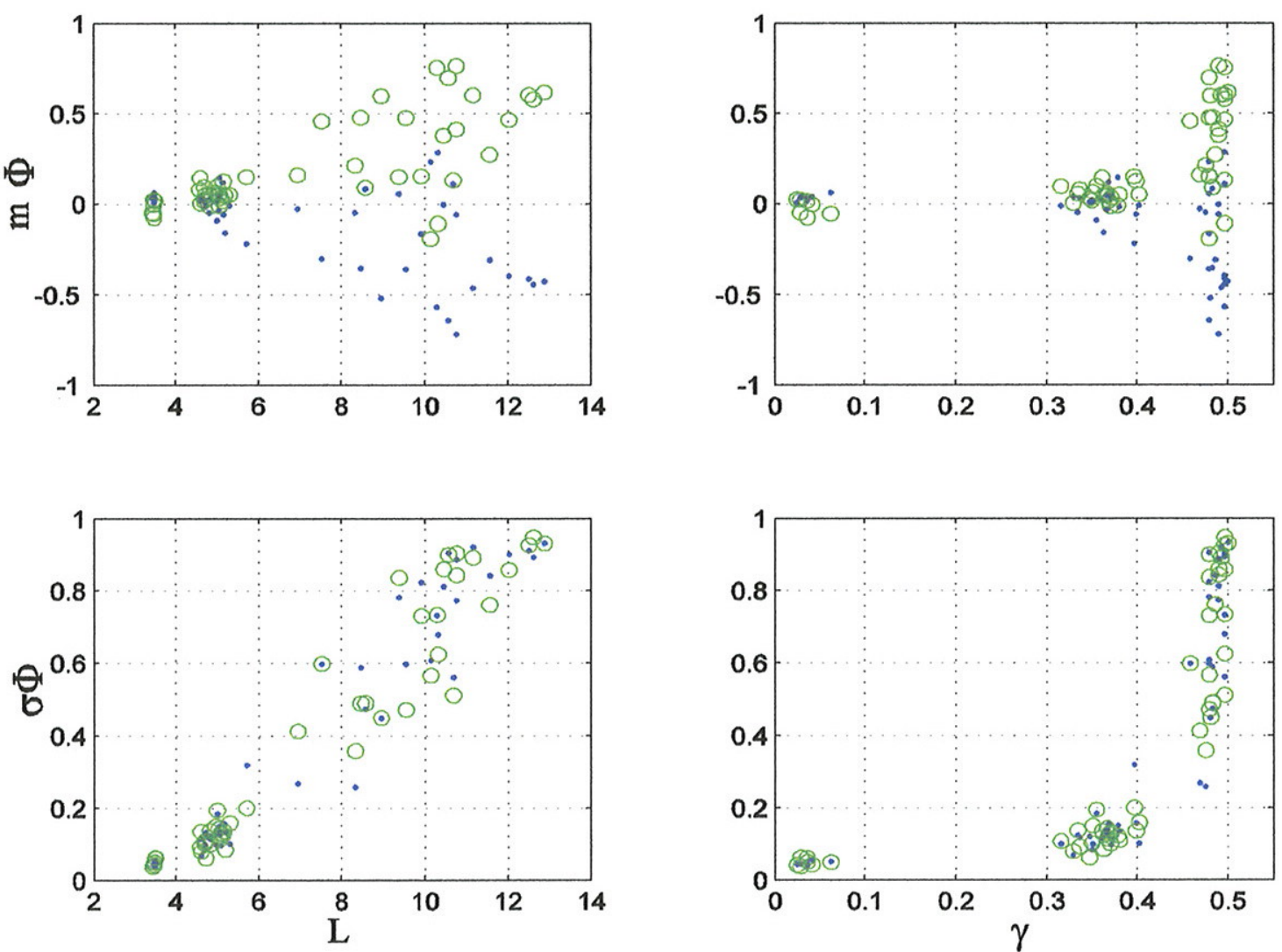

Figura 21: Dependência dos parâmetros $m \Phi$ e $\sigma \Phi$ com os parâmetros $L$ e $\gamma$ para dois conjuntos de simulações de um mesmo sistema mas com diferentes escolhas do nó referência. 

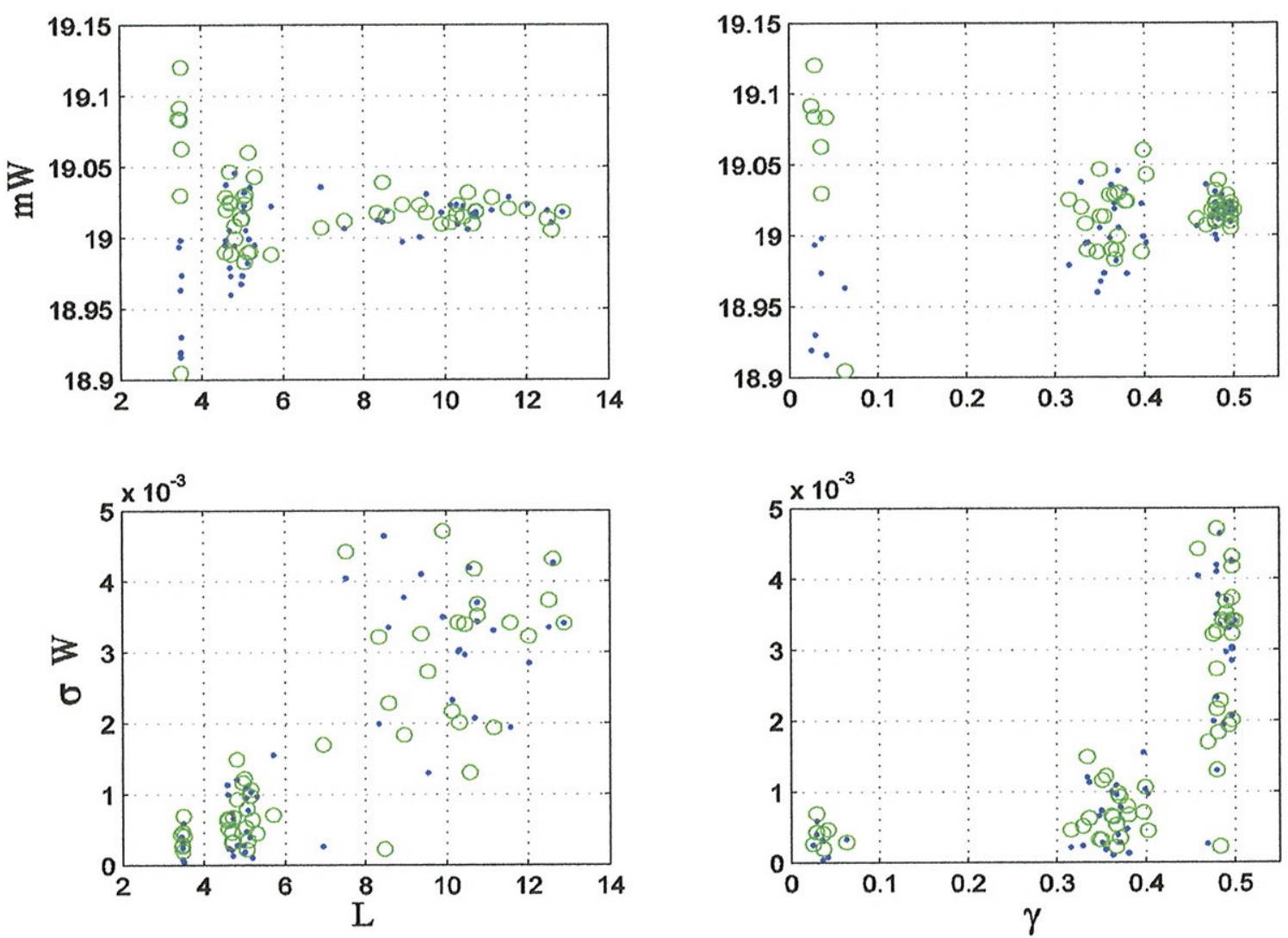

Figura 22: Dependência dos parâmetros $m W$ e $\sigma W$ com os parâmetros $L$ e $\gamma$ para dois conjuntos de simulações de um mesmo sistema mas com diferentes escolhas do nó referência. 

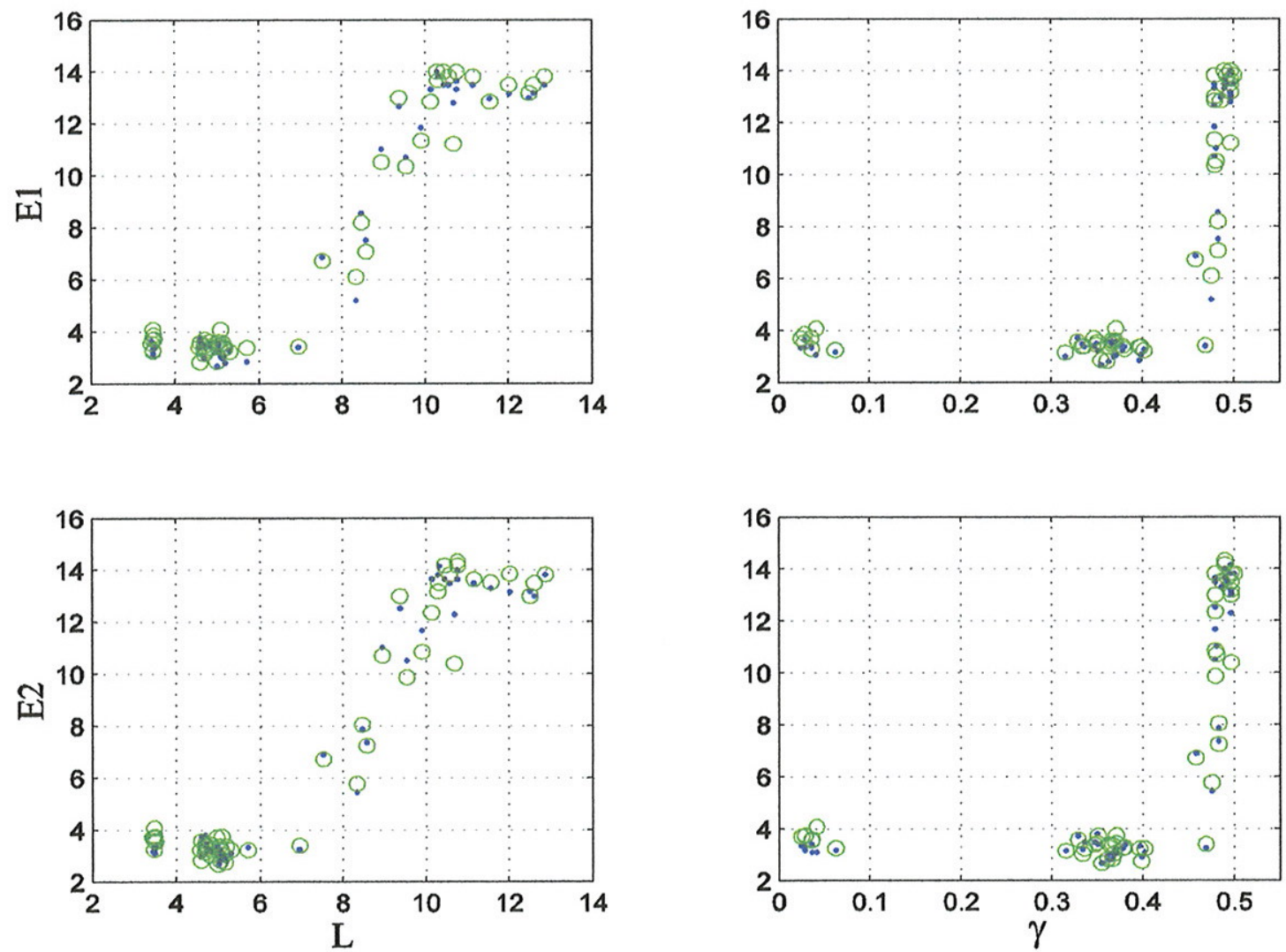

Figura 23: Dependência dos parâmetros $E 1$ e $E 2$ com os parâmetros $L$ e $\gamma$ para dois conjuntos de simulações de um mesmo sistema mas com diferentes escolhas do nó referência.

Nestas figuras, os parâmetros $L$ e $\gamma$, utilizados como indicadores do grau de irregularidade da malha, são apresentados por seus valores calculados e não pelo valor relativo, conforme apresentado na figura 5. Esta opção não representa prejuízo algum para a leitura dos gráficos apresentados, pois os resultados relativos à malha regular correspondem àqueles situados na extrema direita de cada gráfico.

Da análise destas figuras verifica-se:

1. a sensibilidade do parâmetro $m \Phi$ com a escolha do nó referência $(i=1)$, particularmente pela distinção entre os valores apresentado para a malha regular (círculo verde não coincide com ponto azul). Ou seja, apesar das malhas regulares apresentarem os mesmos resultados de simulação, pois representam o mesmo sistema, $m \Phi$ apresenta valores distintos para os dados agrupados segundo os dois conjuntos citados, pois adotam nós distintos como referência; 
2. o aumento do sincronismo do sistema com a diminuição da regularidade da malha, evidenciado pela redução de $\sigma \Phi$, com a diminuição de $L$ e $\gamma$. A dependência de $\sigma \Phi \operatorname{com} L$ é praticamente linear, ou seja não parece haver um súbito afloramento do estado síncrono com pequenas alterações da malha;

3. o aumento no intervalo de valores que a freqüência do sistema no estado final $(\mathrm{mW})$ pode assumir com o aumento da irregularidade do sistema e

4. a equivalência na resposta de $E 1$ e $E 2$ como estimadores do tempo de sincronização e que, por serem conceptivelmente dependentes de $\Phi$, apresentam diferenças sutis entre valores estimados para a sincronização da malha regular.

As figuras 24 a 26 referem-se a dois conjuntos de dados obtidos para simulações no estudo de sistemas que têm as mesmas malhas utilizadas nos conjuntos de simulações apresentadas anteriormente(uma regular e 49 irregulares), mas diferentes distribuições de frequiência de livre curso.

Um conjunto, representado pelos pontos azuis, corresponde aos dados apresentados nas figuras 14 a 16, com a média na distribuição de frequiências de 19,87 rad/s e desvio-padrão de $1,73 \mathrm{rad} / \mathrm{s}$, enquanto o outro conjunto, representado pelas $\mathrm{x}$ vermelhos, tem a distribuição de frequiências caracterizadas pelos valores 19,08 rad/s e 1,80 rad/s respectivamente como média e desvio-padrão. 

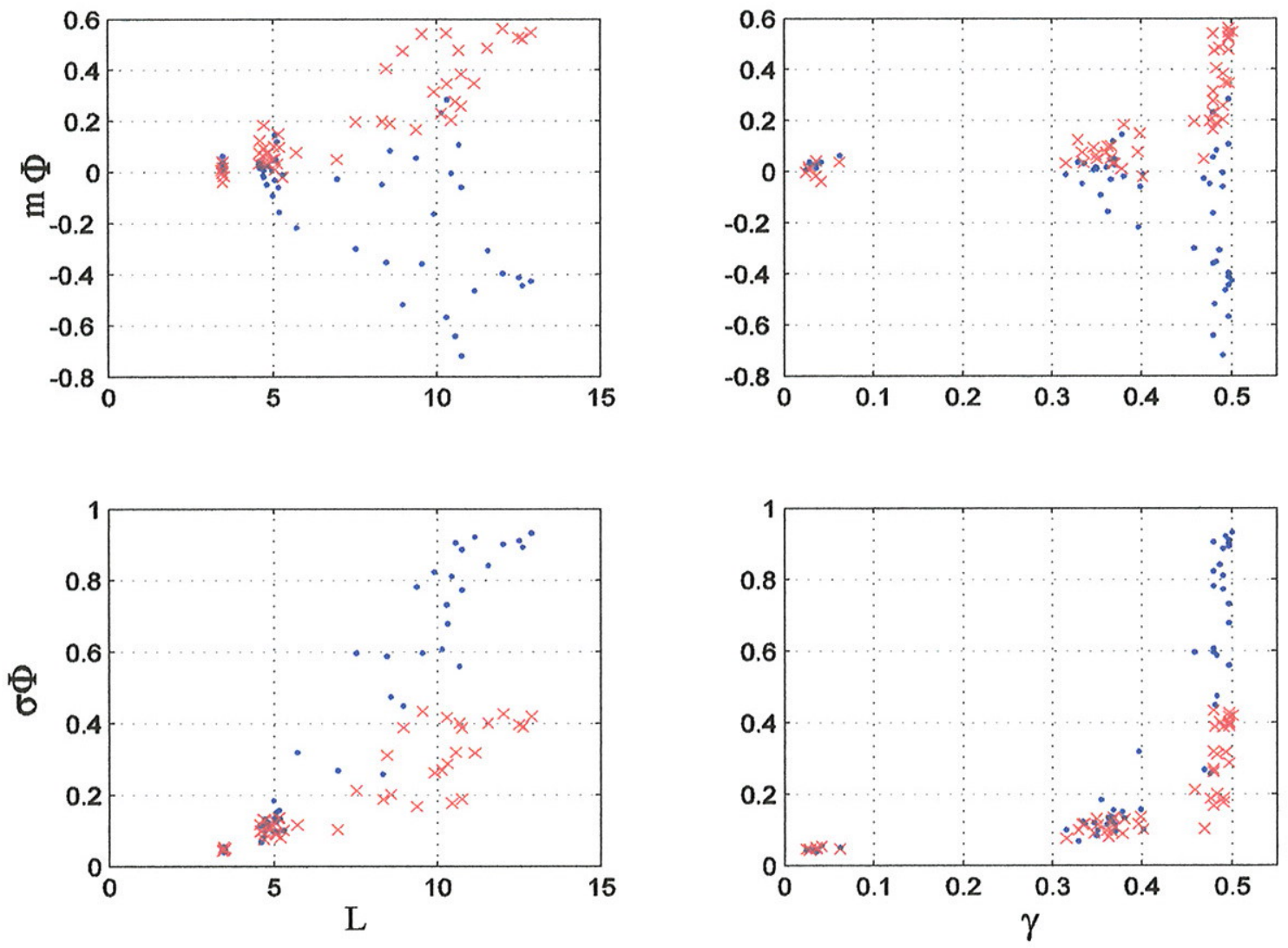

Figura 24: Dependência dos parâmetros $m \Phi$ e $\sigma \Phi$ com os parâmetros gráficos $L$ e $\gamma$ para dois conjuntos de simulações de um sistema $(N=100$ e $k=4)$ relativos a distintas distribuições de freqüência natural. Pontos azuis: freqüência média = 19,87 rad/s; $x$ vermelhos: freqüência média $=19,08 \mathrm{rad} / \mathrm{s}$.

INSTITUTO DERISICA

Serviço de Biblioteca e knformação

Tombo: $\quad 3822$

ex. 1 

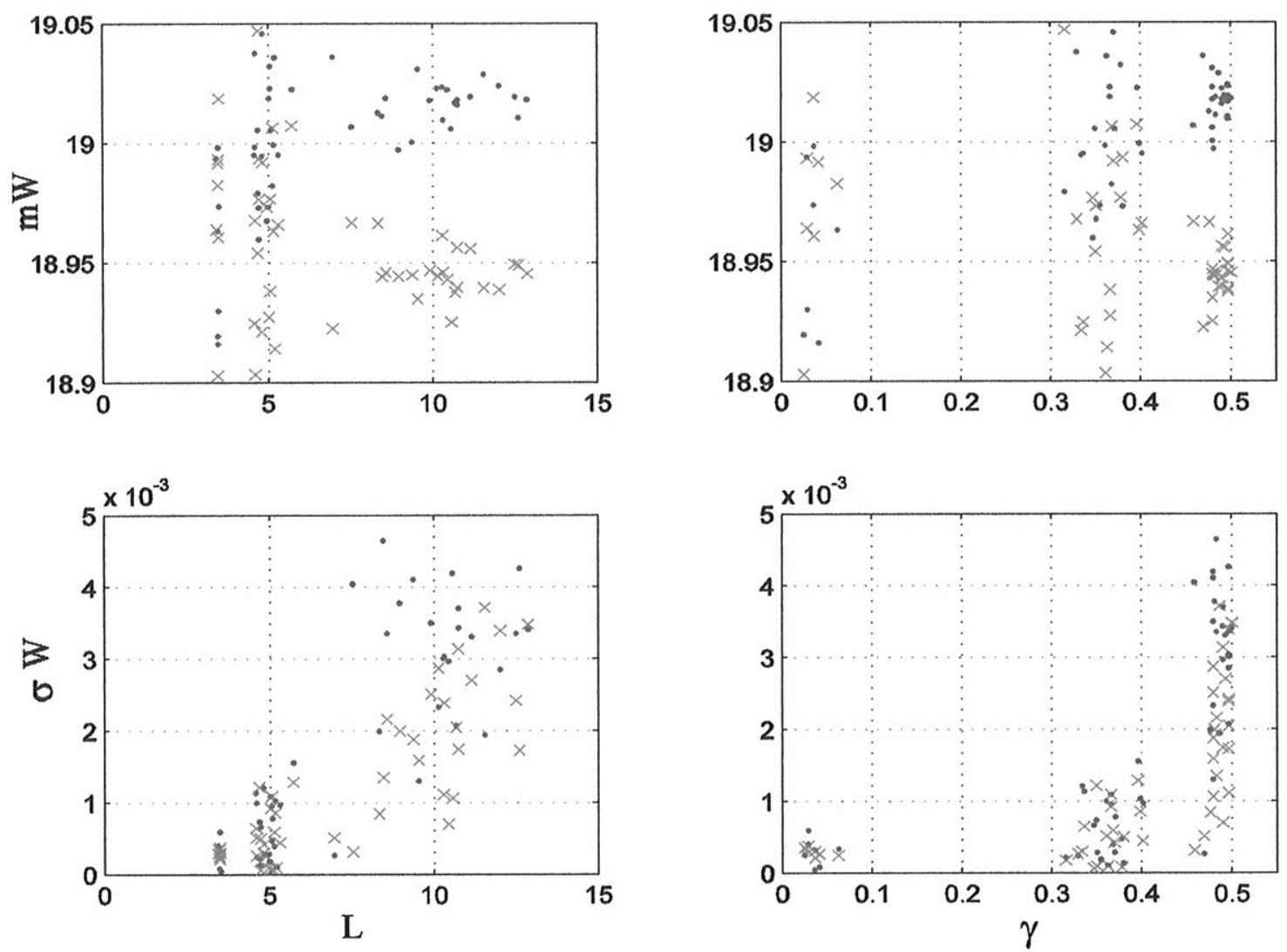

Figura 25: Dependência dos parâmetros $m W$ e $\sigma W$ com os parâmetros gráficos $L$ e $\gamma$ para dois conjuntos de simulações de um sistema $(N=100$ e $k=4)$ relativos a distintas distribuições de freqüência natural. Pontos azuis: freqüência média $=19,9 \mathrm{rad} / \mathrm{s}$; $x$ vermelhos: freqüência média $=19,1 \mathrm{rad} / \mathrm{s}$. 

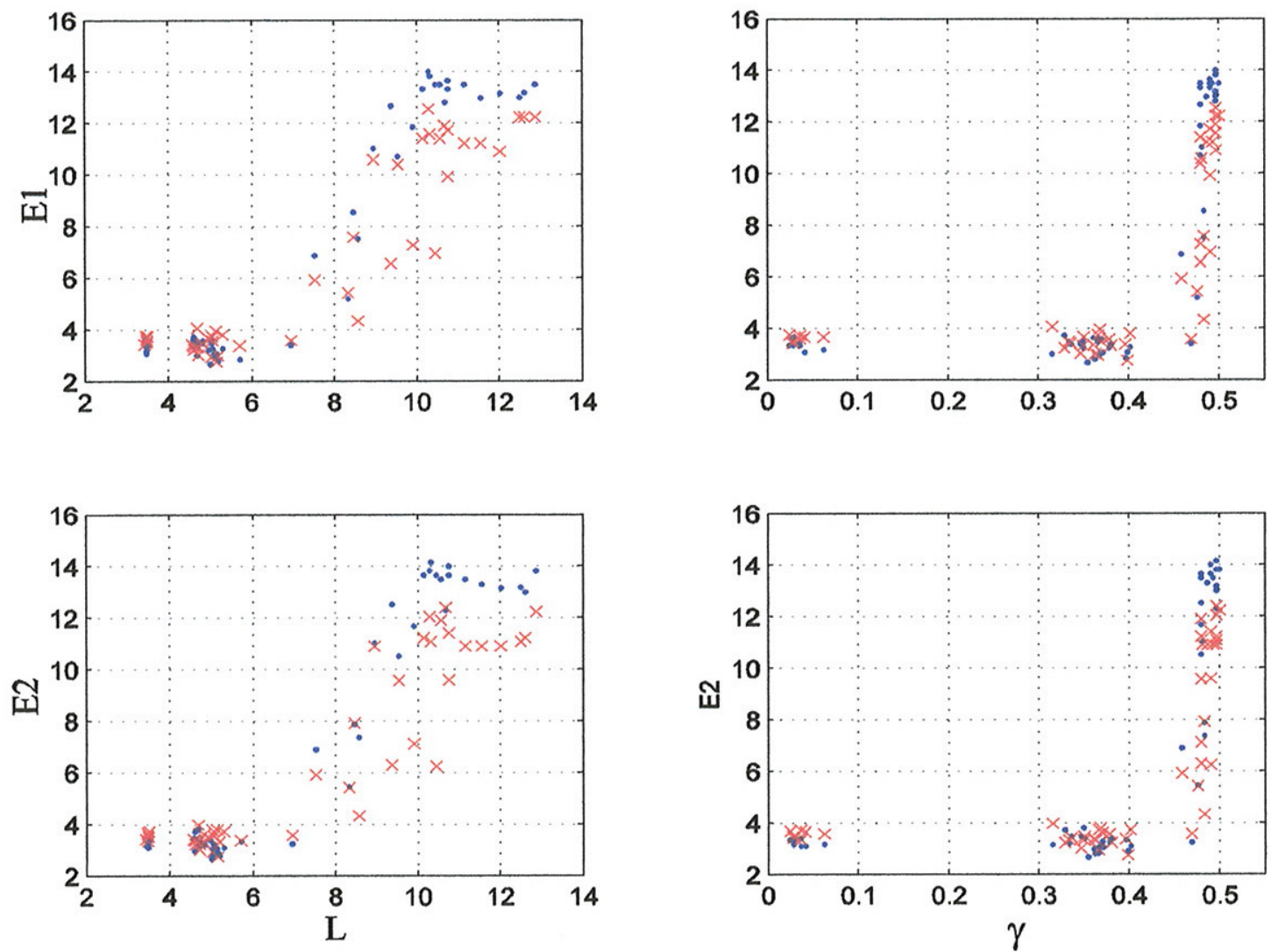

Figura 26: Dependência dos parâmetros $E 1$ e $E 2 \operatorname{com}$ os parâmetros gráficos $L$ e $\gamma$ para dois conjuntos de simulações de um sistema $(N=100$ e $k=4)$ relativos a distintas distribuições de freqüência natural. Pontos azuis: freqüência média = 19,9 rad/s; $x$ vermelhos: freqüência média $=19,1 \mathrm{rad} / \mathrm{s}$.

Da análise destas figuras verifica-se que:

1. os valores da freqüência do estado final $(\mathrm{mW})$ da malha regular de ambos conjuntos, são inferiores ao valores médios das respectivas distribuições de freqüência, esta resposta já fora relatada por Piqueira et al., onde relata-se, para uma malha de 4 nós, a redução da freqüência de oscilação do estado coerente de com o aumento do ganho;

2. a dependência da freqüência de oscilação do estado coerente $(\mathrm{mW})$ com a regularidade da malha, e principalmente o aumento no intervalo de valores que $m W$ assume com o aumento da irregularidade;

3. a reiteração do dependência linear de $\sigma \Phi \operatorname{com} L$ e 
4. para malhas menos irregulares $(\gamma \approx 0,5)$ existe uma diferenciação no tempo de convergência para o estado final, não evidenciada para malhas mais irregulares. A explicação para fato dos sistemas associados a distribuição de frequiências mais larga $(\sigma=1,80 \mathrm{rad} / \mathrm{s})$ ter um período transiente mais curto poderia estar associado ao menor intervalo (range) de freqüências atribuídas ( 9,04 rad/s contra 9,34 rad/s).

As figuras 27 a 32 apresentam os resultados das simulações do estudo de malhas de diferentes ordens $(N=40,100,500$ e 1000) e grau médio 4, com distribuições de freqüência de livre curso parecidas (valor médio próximo a $20 \mathrm{rad} / \mathrm{s}$ com desvio padrão d ordem de $10 \%$ - tabela 2). Adotou-se como parâmetro de exposição os valores relativos de L e $\gamma$ para facilitar comparação entre as malhas de diferentes ordem e permitir a associação com a figura 5 .

Tabela 2: Caracterização da distribuição de freqüências naturais empregadas nas simulações de sistemas de diferentes ordens $(N)$ e grau médio $(k), 4$.

\begin{tabular}{|c|c|c|}
\hline $\boldsymbol{N}$ & Freqüência Média $(\mathbf{r a d} / \mathbf{s})$ & Desvio-padrão $(\mathbf{r a d} / \mathbf{s})$ \\
\hline 40 & 20,06 & 2,36 \\
\hline 100 & 19,87 & 1,73 \\
\hline 500 & 20,11 & 1,95 \\
\hline 1000 & 20,08 & 2,03 \\
\hline
\end{tabular}



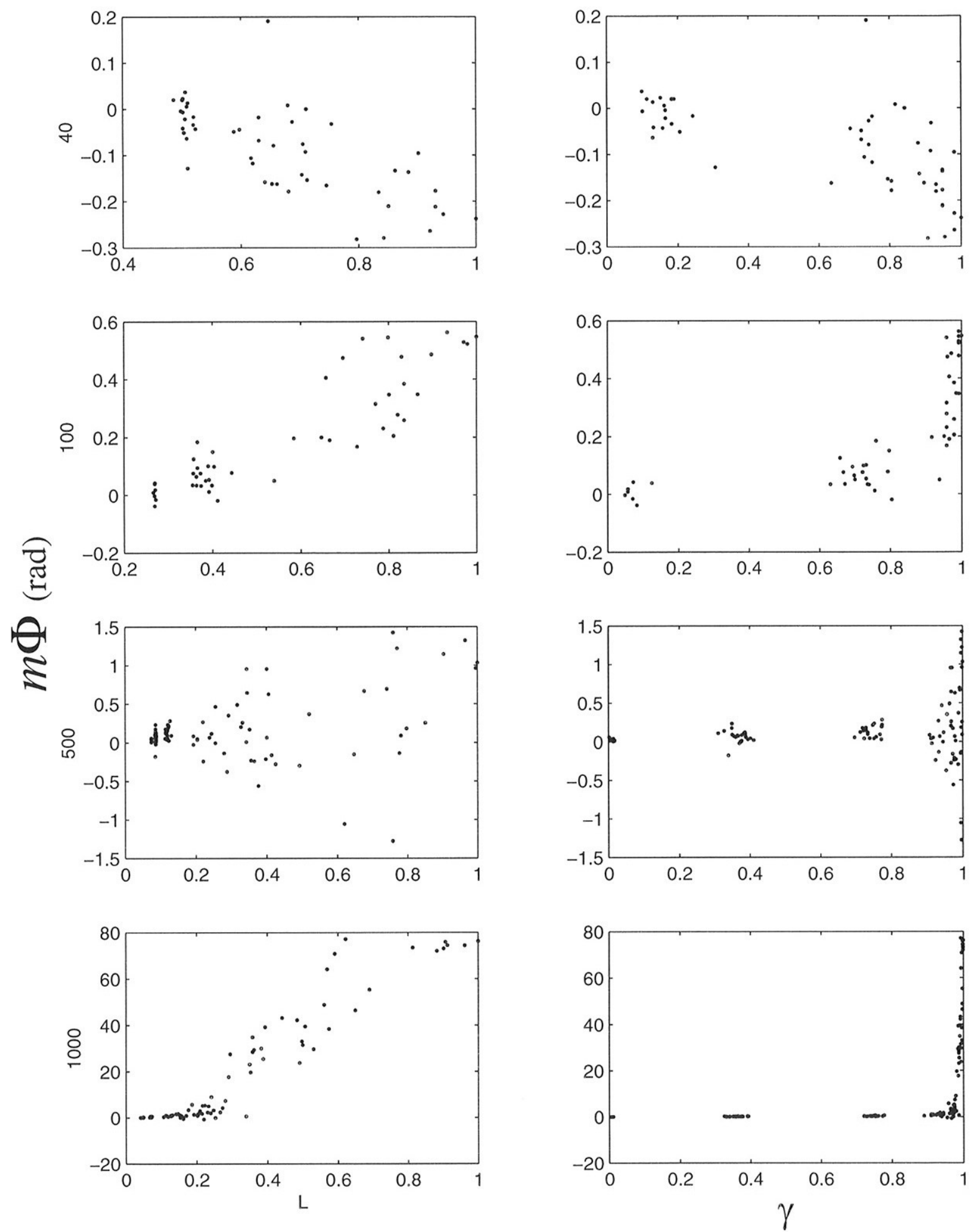

Figura 27: Médias do perfil de diferenças de fase $(m \Phi)$ agrupadas em sistemas de diferentes ordens $(N=40,100,500$ e 1000), em função dos indicadores de regularidade da malha (parâmetros gráficos $L$ e $\gamma$ ). 

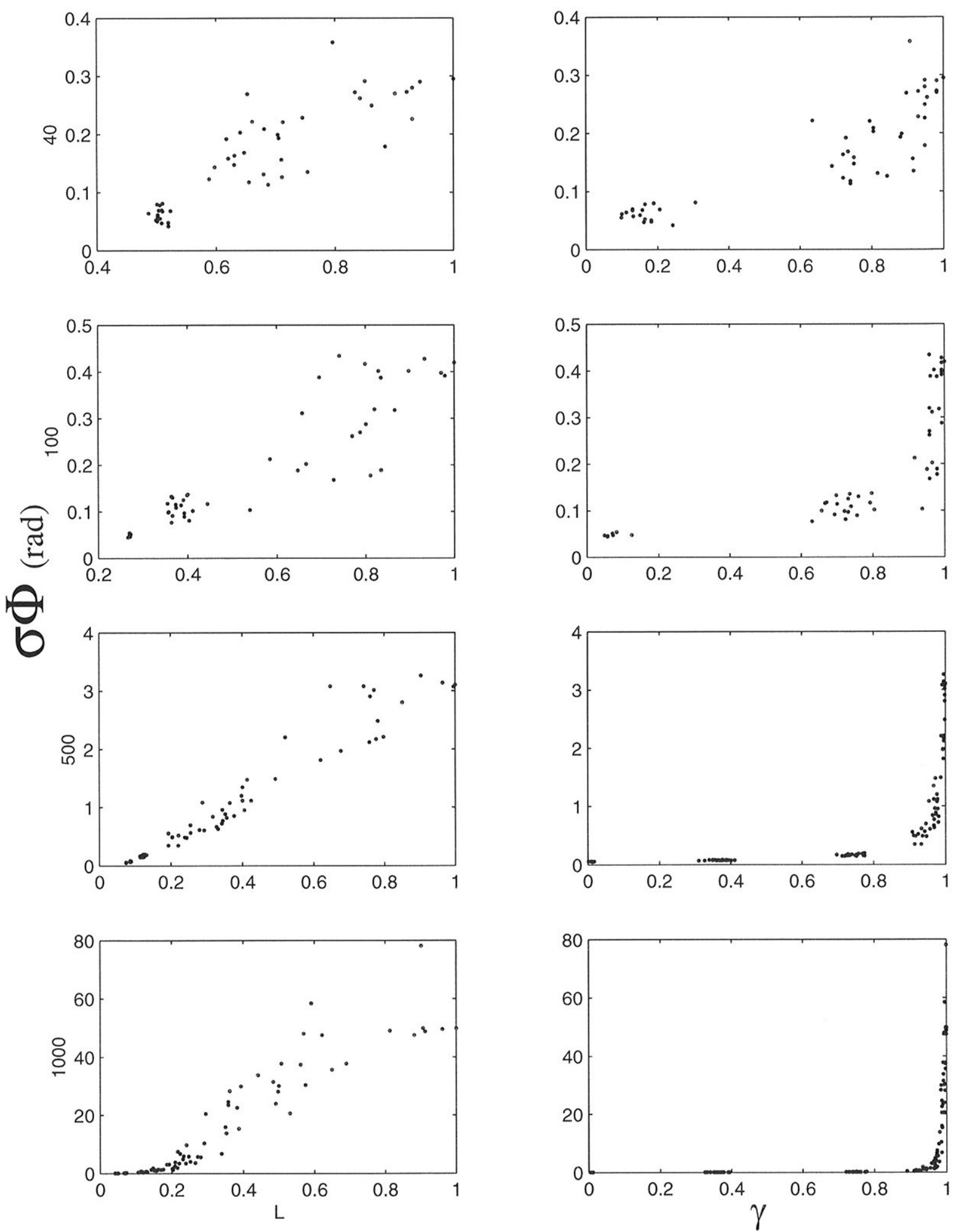

Figura 28: Desvios-padrão do perfil de diferença de fase $(\sigma \Phi)$ agrupadas em sistemas de diferentes ordens $(N=40,100,500$ e 1000), em função dos indicadores de regularidade da malha (parâmetros gráficos $L$ e $\gamma$ ). 
Na análise das figuras 27 e 28, onde são apresentados os gráficos da dependência da diferença de fase média $(m \Phi)$ em função da regularidade das malhas de diferentes ordens $(N=40,100,500$ e 1000), quantificada pelos parâmetros $L$ e $\gamma$, verifica-se o aumento na amplitude do dos parâmetros característicos do sistema com o aumento da ordem da malha, evidenciado pelas diferenças existentes nas escalas dos gráficos apresentados.

Os parâmetros da malha (Comprimento Característico e Clickshness), representados por seus valores relativos, adotando os valores da malha regular correspondente como referência, reiteram a informação dos gráficos apresentados na figura 5 quanto ao alargamento da faixa de valores alcançados por estes parâmetros, principalmente para $L$, com o aumento de $N$. O alargamento da faixa de valores assumidos por $m \Phi$ com o aumento de comprova o aumento da riqueza de padrões fornecidos pelo sistema com o aumento de $N$. Contudo, verifica-se a redução desta riqueza com aumento da irregularidade das malhas.

A redução de $m \Phi$ para valores característicos da malha irregular par altos valores de $\gamma$, variação tão mais abrupta quanto maior o valor de $N$, suscita a dependência de $m \Phi$ com o número de alterações efetuadas nas conexões da malha regular.

A redução de $\sigma \Phi$ com a redução de $L$ e $\gamma$ é observada independentemente do número de nós que compõem o sistema. 

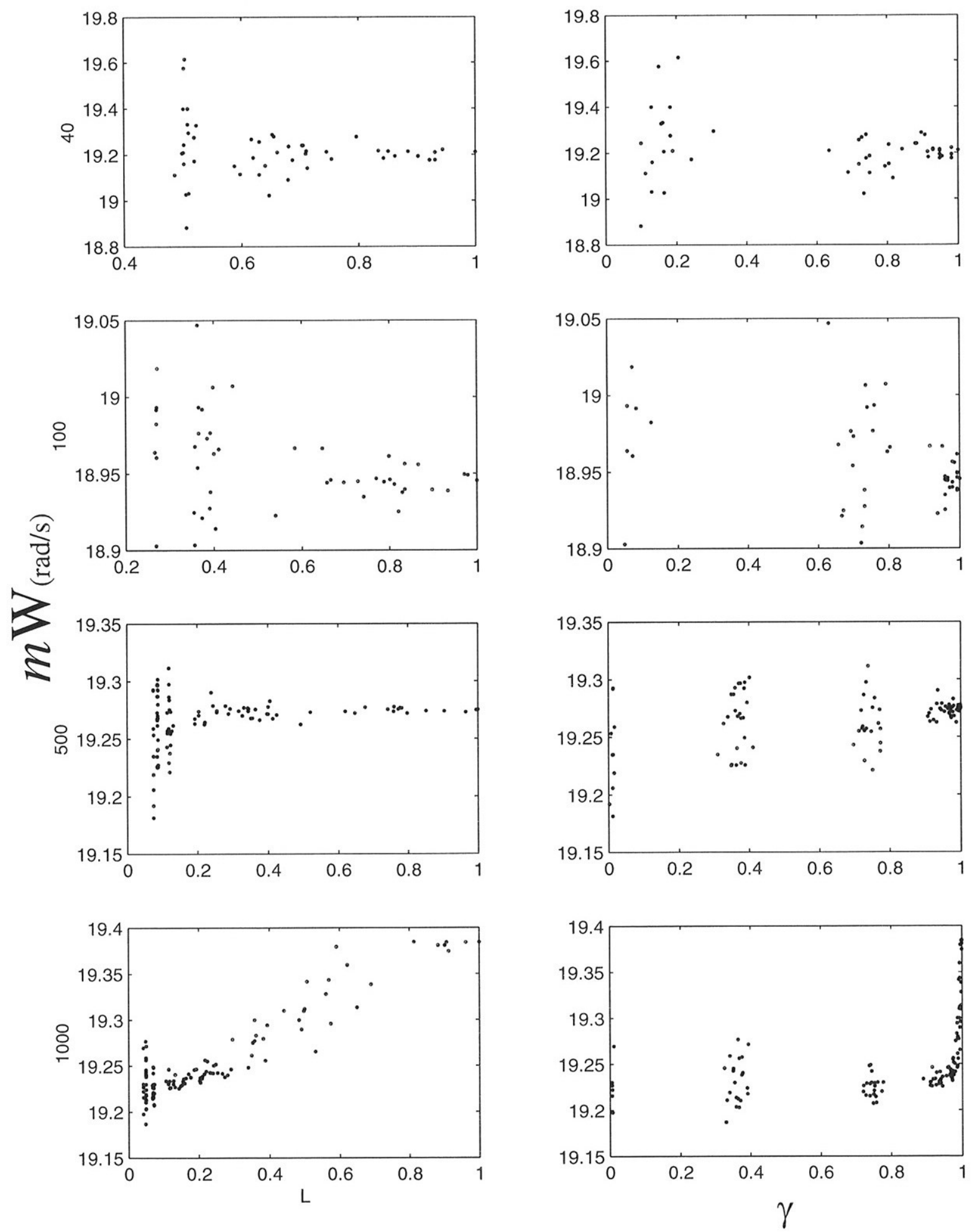

Figura 29: Valor médio da freqüência de oscilação do estado coerente $(\mathrm{m} W)$ agrupados em sistemas de diferentes ordens $(N=40,100,500$ e 1000), em função dos indicadores de regularidade da malha (parâmetros gráficos $L$ e $\gamma$ ). 

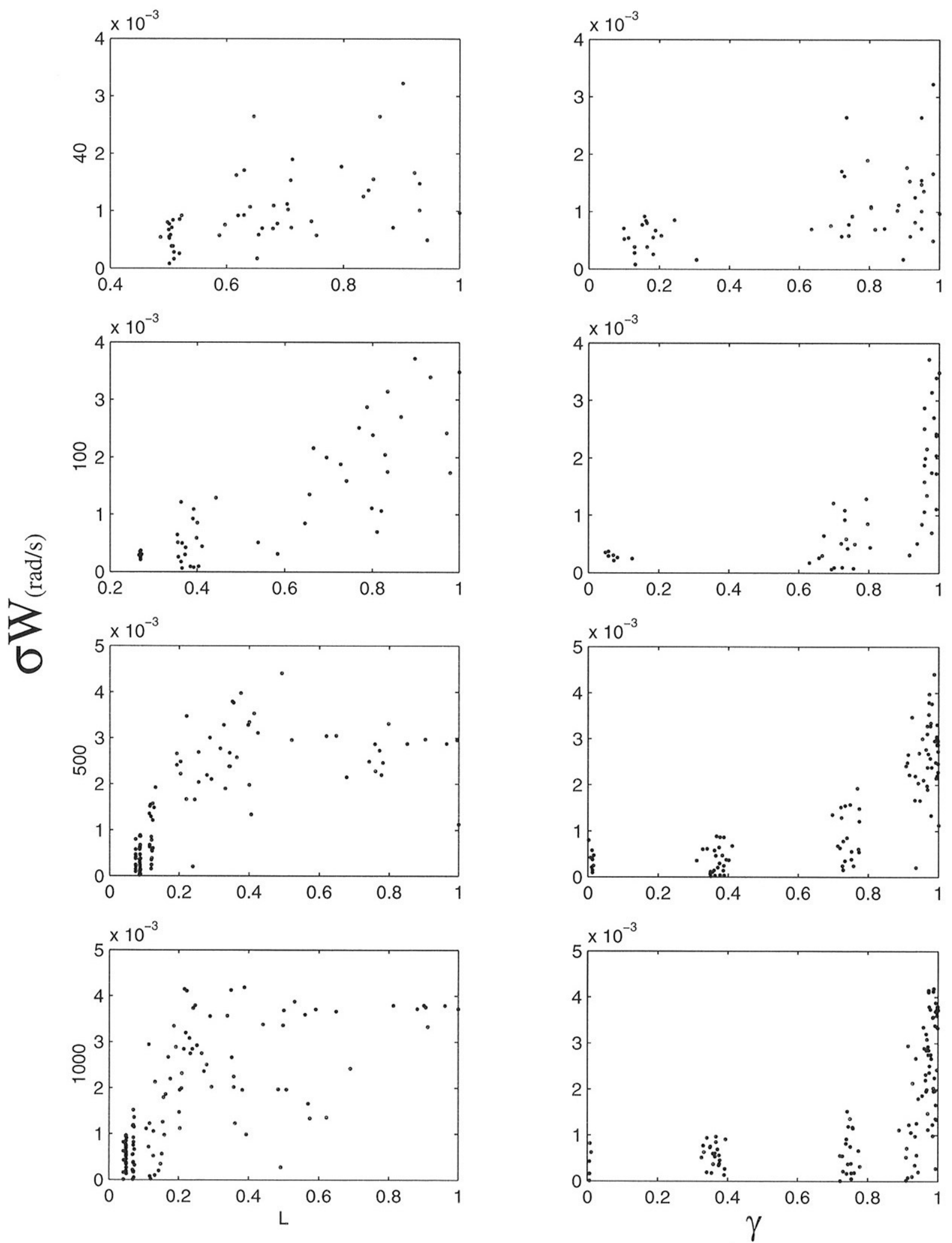

Figura 30: Desvios-padrão da freqüência de oscilação do estado coerente $(\sigma W)$ agrupados em sistemas de diferentes ordens $(N=40,100,500$ e 1000), em função dos indicadores de regularidade da malha (parâmetros gráficos $L$ e $\gamma$ ). 
Da análise das figuras 29 e 30, onde são apresentados os gráficos da dependência da freqüência de oscilação do sistema no estado coerente e seu desvio-padrão (respectivamente $m W$ e $\sigma W$ ) em função da regularidade das malhas de diferentes ordens $(N=40,100,500$ e 1000), quantificada pelos parâmetros $L$ e $\gamma$, os valores de $m W$ são sistematicamente inferiores à freqüência média da distribuição de freqüências de livrecurso. Verifica-se também a ampliação dos valores de distribuição de $m W$ com a redução da regularidade da malha. Porém, para malhas $\operatorname{com} N=1000$, anteriormente à ocorrência desta ampliação, existe uma queda abrupta de $m W$, para reduções de g nas proximidades do valor característico da malha regular. Pode-se atribuir à existência de um valor absoluto para comprimento característico para o qual a dispersão dos valores de $m W$ atinge um o valor mínimo, o que, por sua vez poderia estar associado à uma velocidade de propagação da informação no sistema.

O aumento da precisão na determinação de $m W$ com o aumento da irregularidade da malha, evidenciado pela resposta de $\sigma W \operatorname{com} L$ e $\gamma$. Este fato não significa, porém, uma maior exatidão no valor determinado e sim o aumento de sincronismo (também evidenciado por $\sigma \Phi)$. O aumento de sincronismo minimiza a variação na determinação das freqüências de oscilação dos nós $(W j)$. 
E1
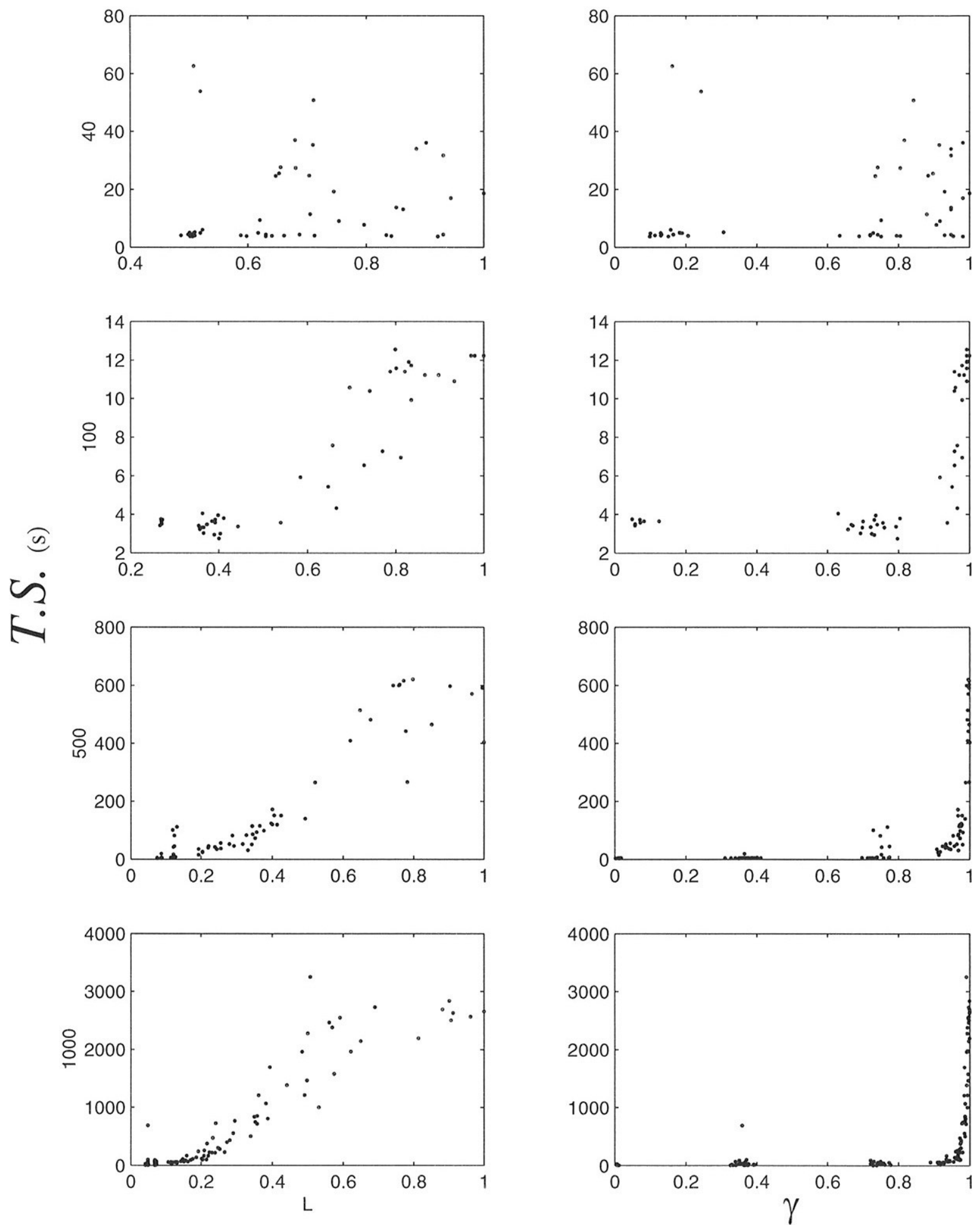

Figura 31: Estimativas do tempo de sincronização (T.S.) calculadas pelo parâmetro E1, agrupados em sistemas de diferentes ordens $(N=40,100,500$ e 1000), em função dos indicadores de regularidade da malha (parâmetros gráficos $L$ e $\gamma$ ). 

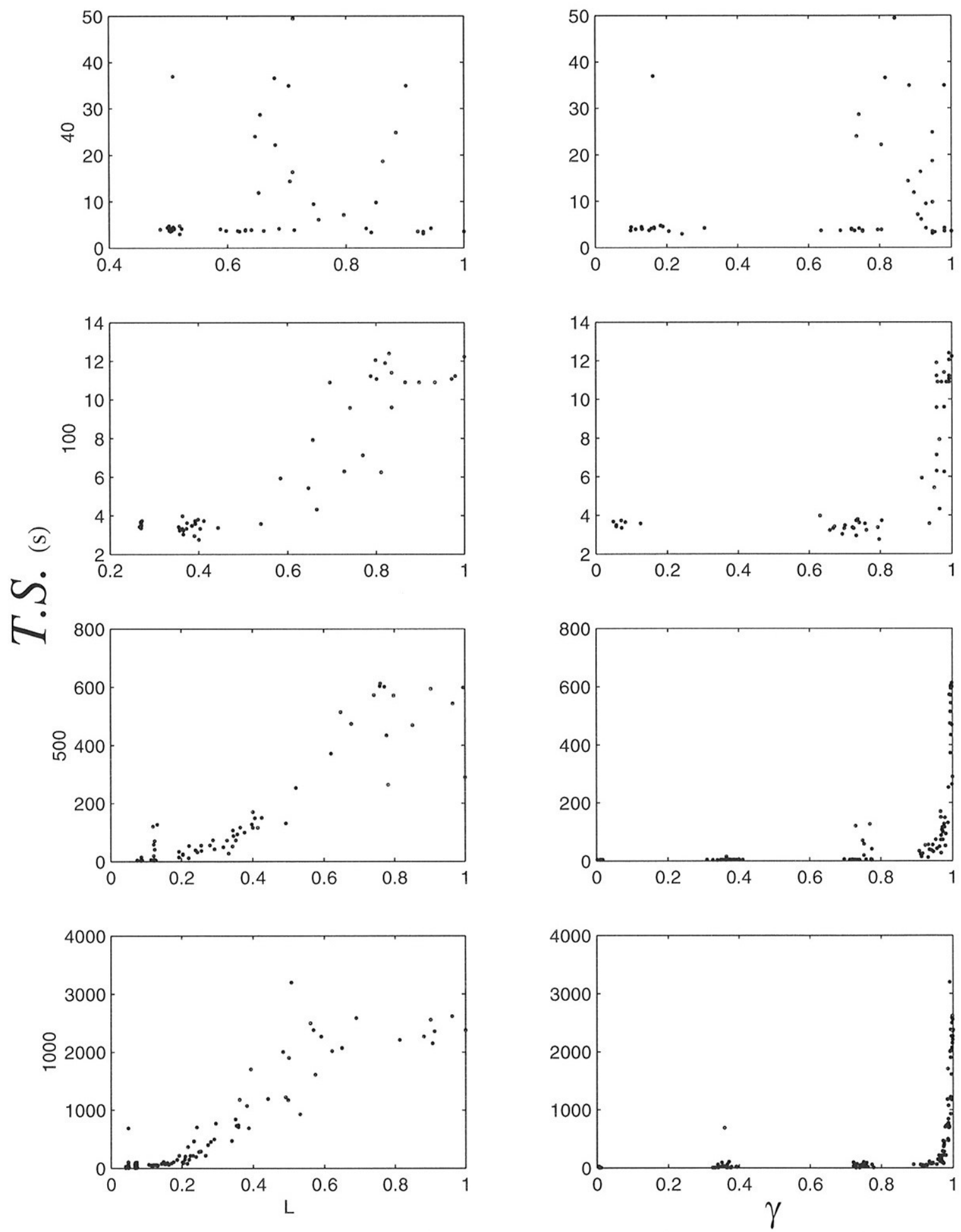

Figura 32: Estimativas do tempo de sincronização (T.S.) calculadas pelo parâmetro E2, agrupados em sistemas de diferentes ordens $(N=40,100,500$ e 1000), em função dos indicadores de regularidade da malha (parâmetros gráficos $L$ e $\gamma$ ). 
As figuras 31 e 32 mostram os gráficos do tempo de sincronização (T.S.), utilizando respectivamente os parâmetros E1 e E2 na avaliação, em função da regularidade das malhas para os mesmos sistemas analisados nas figuras 27 a 30. Da análise destes gráficos verificase a semelhança nas respostas apresentadas pelos dois estimadores, respondendo resultados quantitativamente equivalentes na grande maioria dos casos. Observam-se, também, o aumento de T.S. malha regular com o aumento de $N$ e a diminuição com a redução da regularidade da malha (à exceção dos resultados apresentados para $N=40$ ). Constata-se o comportamento qualitativamente equivalente a $\sigma \Phi$ para as malhas com $N=100,500$ e 1000 sugerindo a dependência do grau de sincronia com a duração do período transiente. 


\section{Conclusões}

Assumindo o perfil de diferenças de fase e a freqüência de oscilação como as informações associadas a um sistema composto pelo acoplamento de PLLs, verificam-se respostas bem distintas destes parâmetros frente à alterações da topologia do sistema. Ou seja, apesar da co-participação da estrutura de acoplamento dos osciladores e das características elementares de cada oscilador na determinação das características de operação do sistema, e aceitando-se a associação entre dispersão de informação num sistema e a organização do mesmo, pode-se concluir que, caso a relação entre as fases seja o parâmetro a ser preservado, esta informação deve estar distribuída entre os elementos que integram o sistema (osciladores), visto ser este parâmetro suscetível a menores alterações para sistemas de baixa regularidade. Em contrapartida, caso a freqüência de oscilação seja o parâmetro a ser preservado, essa informação deve estar alocada preferencialmente em pontos específicos do sistema, visto haver uma tendência deste parâmetro apresentar um aumento no intervalo de valores de caracterização do estado final para malhas de regularidade baixa.

Portanto, no estudo de sistemas representados pela associação de osciladores, e considerando-se a possibilidade da coexistência de diferentes estratégias na preservação de informação nestes sistemas, exige-se a averiguação da pertinência da transposição do modelo adotado no estudo de um sistema quando o objeto/instrumento de análise é distinto daquele de origem. Esta averiguação resguarda o estudo do risco de, no processo de redução da análise do problema, melhorar-se a resposta de um parâmetro de interesse com a simultânea descaracterização do sistema global pela alteração de um parâmetro desprezado.

Os resultados obtidos além de ratificarem a validade da proposição de HOPPENSTEADT da utilização do PLL em redes neurais concebidas para o reconhecimento de padrões, relaxam as condições impostas ao sistema (a princípio formado por PLLs com freqüência de livre curso idênticas) e sinalizam a possibilidade do aumento na precisão dos padrões reconhecidos com o aumento do número de PLLs na rede. 
Como continuidade a este estudo ficam o aprofundamento dos efeitos de atraso na dinâmica do sistema e o questionamento da existência de uma velocidade de propagação de informação suscitado pela análise dos $m W$ para malhas de diversas ordens. 


\section{Apêndice}

Apresenta-se, com o intuito de ilustração, acrescentando-se informações expostas no texto, alguns resultados referentes a estudos realizados e que serviram de embasamento na adoção de alguns parâmetros de simulação.

A figura $\mathrm{A} 1$, ilustra a redução do período transiente com o aumento do ganho a partir da apresentação da evolução do parâmetro E1 para 4 valores de ganho diferentes $(\mathrm{G}=50 \mathrm{~V} / \mathrm{rad} . \mathrm{s}, 60 \mathrm{~V} / \mathrm{rad} . \mathrm{s}, 100 \mathrm{~V} / \mathrm{rad} . \mathrm{s}$ e $140 \mathrm{~V} / \mathrm{rad} . \mathrm{s}$. $)$ compreendidos na faixa de retenção do estado coerente.

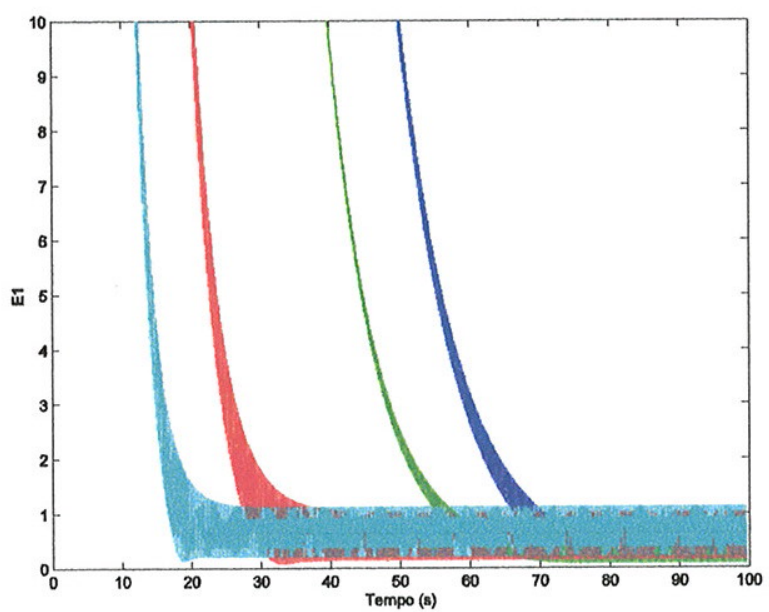

Figura A1: Evolução do parâmetro $E 1$ para sistemas com ganhos diferentes. Em azul, Ganho = 50V/rad; verde: 60; vermelho:100 e azul claro 140 .

Valores diferentes do ganho também influenciam nos valores da freqüência de coerência (figura A2) e na amplitude do perfil diferença de fase (figura A3). Na figura A2, são apresentados nos gráficos superiores a estimativa da freqüência de oscilação do estado coerente $(W)$ para todos os nós de uma malha $(\mathrm{j}=1 . .100)$ para dois valores de P.I. $(0,0025 \mathrm{~s}$, à esquerda e $0,025 \mathrm{~s}$, à direita $)$ obtidas para simulações empregando 4 valores de ganho, tal qual a figura A1. No gráfico inferior, compara-se a influência do P.I. na determinação dos valores de $\mathrm{Wj}$. Na figura $\mathrm{A} 3$ repete-se o expediente, mas analizando os efeitos do ganho e de P.I. no perfil de diferenças de fase. A análise destas figuras reitera aindiferença dos parâmetros $\mathrm{mW}$ e $\mathrm{mF}$ e $\mathrm{sF}$ em relação ao P.I. adotado mas evidencia a influência do ganho na determinação do valor de seus parâmetros. 

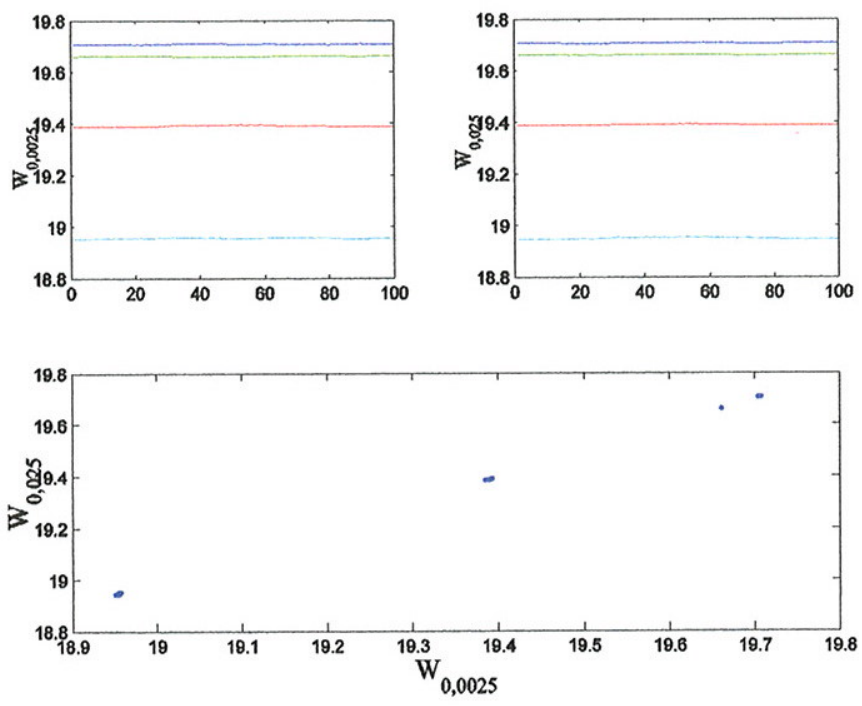

Figura A2: Médias das freqüências de oscilação, avaliadas para cada nó da malha, obtidas para simulações utilizando dois passos de integração distintos (P.I. $=0,0025$ no alto a esquerda e 0,025 s no alto à direita) e empregando diferentes valores para o ganho distintos; azul : 50; verde :60; vermelho:100 e azul claro: 140.
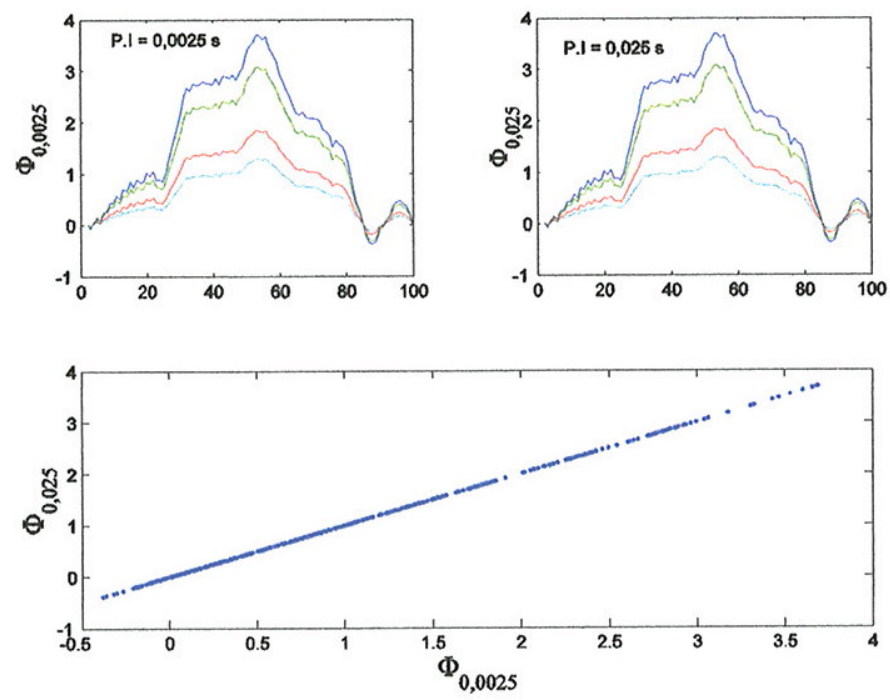

Figura 31: Diferença de fase média, avaliadas para cada nó da malha, obtidas para simulações utilizando dois passos de integração distintos (P.I. $=0,0025$ no alto a esquerda e $0,025 \mathrm{~s}$ no alto à direita) e empregando diferentes valores para o ganho distintos; azul : 50; verde :60; vermelho:100 e azul claro: 140. 


\section{Referências}

Aoyagi ,T., (1995), Network of Neural Oscillators for Retrieving Phase Information, Physical Review Letters, vol.74, No. 20, pp-4075-4078.

Best, R. E., (1984), Phase-Locked Loops, Theory, Design and Applications, McGraw-Hill, New York.

BuCK, J., (1988), Synchronous rhythmic flashing of fireflies, Quarterly review of Biology, 63, pp. 265-269, a partir de Watts(1999).

CoHEn, A.C. ET AL., (1982) The Nature of the coupling between segmental oscillators in the lamprey spinal generator for locomotion: a mathematical model, Journal of mathematical biology, 13, pp-345-369.

De Souza VIEIRA ET AL., (1991) Nonlinear Dynamics of Self-Synchronizing Systems, International Journal of Bifurcation and Chaos, Vol.1, No.3, pp-691-699.

Glass, L., (1997) Relógio ao Caos: os Ritmos da Vida, Edusp, São Paulo.

Goldzstein., G. E Strogatz, S.H., (1995) Stability of Syynchronization in Networks of Digital Phase-Locked Loops, International Journal of Bifurcation and Chaos biology, Vol.5, No.4, pp-983-990.

Hanselman, D. E LitTlefield, B., (1996), Mastering Matlab: a comprehensive tutorial and reference, Simon and Schuster, Upper Saddle River.

HARARI, F., (1972), Graph Theory, Addison-Wesley, Massachusetts.

HoppensteadT, F.C. E IzHIKEvich, E.M., (2000), Pattern recognition via synchronization in phase-locked loop neural networks, IEEE Transactions on neural network, vol.11, No.3, Maio.

KindZElskiI, L.A. E PetTy, H.R., (2002), Apparent role of traveling metabolic waves in oxidant release by living neutrophils, Proceedings of the National Academy of Science, vol.99, No. 14, July, pp. 9207-9212.

Kopell, N., (1995), Chains of coupled oscillator, The handbook on the brain theory and neural networks. Ed. Michael A. Arbibi et al., MIT Press, Massachussets, pp. 78-183.

Kuramoto, Y., (1975), Self entrainment of a population of coupled non-linear oscillators, International Symposium on Mathematical Problems in Theoretical Physics, Lectures Notes in Physics, Vol.39, ed. H. Araki, Springer, New York 
Kuramoto, Y., (1995), Collective Behavior of Coupled Oscillators, The handbook on the brain theory and neural networks. Ed. Michael A. Arbibi et al., MIT Press, Massachussets, pp. 203-206.

LAGO-FERNANDEZ. ET AL., (2000), Fast Response and Temporal Coherent Oscillations in Small-World Networks, Physical Review Letters, vol.84, No. 12, pp-2758-2761.

PiqueIRA, J.R.C. ET AL., (2003), Computing with phase locked loops: choosing gains and delays, IEEE Transactions on neural networks, vol.14, no.1, Janeiro;

PIQUEIRA, J.R.C. E MONTEIRO, L.H.A., Considering second-harmonic terms in the operation of the phase detector for second order phase-locked loops, a ser publicado em 2003.

SATOH, K., (1989), Computer experiment on cooperative Behavior of a network of interacting nonlinear oscillators, Journal of the Physical Society of Japan, Vol.58, No.6, June, pp.2010-2012.

TANAKA, H. ET AL. , (1997), Stability of synchronized states in one dimensional networks of second order PLLs, International Journal of Bifurcation and Chaos, Vol. 7, No.3, pp.681-690.

Tortora, G. J., (2000), Corpo Humano: Fundamentos de Anatomia e Fisiologia, $4^{\mathrm{a}}$ edição, Antena 1 Editora, Porto Alegre.

WatTs, D.J. (1999), Small World, Princeton University, New Jersey.

Watts, D.J. E Strogatz, S.H, (1998) Collective dynamics of 'small-world' networks, Nature, Vol. 393, junho, pp. 440-442.

Wilson , R.J., E Watkins, J.J. (1990), Graphs: an introductory approach, New York: Wiley. 